\title{
Finite Beta Toroidal Plasmas
}

\author{
Glenn Bateman \\ D. B. Nelson \\ D. J. Sigmar \\ N. A. Uckan
}

OAK RIDGE NATIONAL LABORATORY OPERATED BY UNION CARBIDE CORPORATION - FOR THE DEPARTMENT OF ENERGY 


\section{DISCLAIMER}

This report was prepared as an account of work sponsored by an agency of the United States Government. Neither the United States Government nor any agency Thereof, nor any of their employees, makes any warranty, express or implied, or assumes any legal liability or responsibility for the accuracy, completeness, or usefulness of any information, apparatus, product, or process disclosed, or represents that its use would not infringe privately owned rights. Reference herein to any specific commercial product, process, or service by trade name, trademark, manufacturer, or otherwise does not necessarily constitute or imply its endorsement, recommendation, or favoring by the United States Government or any agency thereof. The views and opinions of authors expressed herein do not necessarily state or reflect those of the United States Government or any agency thereof. 


\section{DISCLAIMER}

Portions of this document may be illegible in electronic image products. Images are produced from the best available original document. 
Printed in the United States of America. Available from National Technical Information Service

U.S. Department of Commerce

5285 Port Royal Road, Springfield, Virginia 22161

Price: Printed Copy $\$ 5.25$; Microfiche $\$ 3.00$

This report was prepared as an account of work sponsored by an agency of the United States Government. Neither the United States Government nor any agency thereof, nor any of their employees, contractors, subcontractors, or their employees, makes any warranty, express or implied, nor assumes any legal liability or responsibility for any third party's use or the results of such use of any information, apparatus, product or process disclosed in this report, nor represents that its use by such third party would not-infringe privately owned rights. 
ORNL/TM-6273

Dist. Category UC-20g

Contract No. W-7405-eng-26

FUSION ENERGY DIVISION

FINITE BETA TOROIDAL PLASMAS

Glenn Bateman

D. B. Nelson

D. J. Sigmar

N. A. Uckan

Date Published - May, 1978

NOTICE

This report was prepared as an accourtit of work sponsored by the United States Covernment. Neither the United States nor the United States Department of Energy, nor any of their employees, nor any of their contractors, subcontractors, or their employees, makies any warnaty, express or implied, or assumes any legal the accuracy, completeness or usefulness of any information, apparatus, product or process disclosed. of represents that its "lo, would not infringe privately owned rights.

NOTICE This document contains information of a preliminary nature. It is subject to revision or correction and therefore does not represent a final report.

Prepared by the OAK RIDGE NATIONAL LABORATORY

Oak Ridge, Tennessee 37830

operated by

UNION CARBIDE CORPORATION

for the

DEPARTMENT OF ENERGY 


\section{THIS PAGE \\ WAS INTENTIONALLY \\ LEFT BLANK}


CONTENTS

ABSTRACT •. . . . . . . . . . . . . . . . . . . . . . v v

I. HIGH BETA TOKAMAK INSTABILITIES . . . . . . . . . . . . 1 Abstract . . . . . . . . . . . . . . . . . : 1

1. Experimental Observations ............... 1

2. MHD Instablitities .................. . 3

3. Concluding Remarks ................. 5

Acknowledgments ..... . . . . . . . . . . 5

References .................... 5

II. FUNDAMENTAL TIME SCALES FOR FLUX CONSERVING TOKAMAK HEATING AND CERTAIN GLOBAL FCT EQUILIBRIUM PROPERTIES . • • . • . . 10

Abstract . . . . . . . . . . . . . . . . 10

1. Time Scales for Flux Conservation . . . . . . . . 10

2. Resistive Decay of the $q(\psi)$-Profile . . . . . . . . 12

3. Global Equilibrium Characteristics of Noncircular Flux Conserving Tokamaks . . . . . . . . . . . 13

References ..................... 15

III. INTENSE NEUTRAL BEAM HEATING IN THE ADIABATIC.-

APPROXIMATION ................... 16

1. Introduction . . . . . . . . . . . . . 16

2. Equations of Motion . . . . . . . . . . . . . . 17

3. Flux Surface Averaged Equations . . . . . . . . 19

4. Poloidal Flux as Independent Variable . . . . . . . 22

5. Applications . . . . . . . . . . . . . . 23

Acknowledgments . . . . . . . . . . . . . . 26

Appendix .. . . . . . . . . . . . . . . . . 26

References .................... 28

IV. THE ELMO BUMPY TORUS - PRESENT AND FUTURE . . . . . . . . . 33

1. Introduction . . . . . . . . . . . . . . 33

2. The EBT Plasma . . . . . . . . . . . . . 33

3. Plasma Heating in EBT . . . . . . . . . . 34

4. Present and Near-Future EBT Experiments . . . . . . 35

5. Experimental Results . . . . . . . . . . . . 35 
6. Theoretical Considerations . . . . . . . . . 37

7. Reactor Application ............. . 39

References ................. 4 40 
ABSTRACT

These four papers on high- $\beta$ tokamak instabilities, fundamental time scales for flux conserving tokamak heating, intense tokamak heating in the adiabatic approximation, and the Elmo Bumpy Torus were presented at the Workshop on High Beta Tokamaks held at Varenna, Italy on September 1-9, 1977. They will be included in the proceedings of that meeting, to be published by the Department of Energy. 
HIGH BETA TOKAMAK INSTABILITIES

Glenn Bateman

ABSTRACT

Theoretical predictions. using the ideal MHD model indicate that large scale ballooning modes should appear when the average beta is raised above $1 \%$ to $2 \%$ in present-day tokamak geometries or $5 \%$ to $10 \%$ in more optimized geometries. The onset of instability is predicted to be sudden and the behavior of ballooning modes to be strikingly different from the sawtooth and Mirnov oscillations experimentally observed at low- $\beta$. Conditions close to the predicted onset were achieved in ORMAK with no noticeable change in plasma behavior. Experiments are planned for the ISX tokamak to test the beta limit.

\section{EXPERIMENTAL OBSERVATIONS}

The ORMAK experiment at Oak Ridge National Laboratory has demonstrated several of the prerequisites needed to raise tokamak beta to several percent. First, a volume-averaged beta of about $1 \%$ was achieved ${ }^{1}$ when $340 \mathrm{~kW}$ of coinjected neutral beam power were used in a plasma with low $q$ value $\left(q_{\text {edge }}=2.5\right)$, low density $\left(\vec{n}_{e} \sim 1.5 \times 10^{13}\right)$, and low toroidal magnetic field $\left(B_{\text {tor }}=10.5 \mathrm{kG}\right.$ ). The volume-averaged beta of the background plasma was $0.4 \%$ with the remainder of the pressure coming from the fast beam particles. Central beta values were $\sim 1.4 \%$ for the background plasma and $\sim 3 \%$ total. No fundamental changes were observed in the plasma characteristics - no voltage spikes or excessively large Mirnov oscillations. Neither was toroidal spinup of the plasma from the neutral beam momentum observed.

Second, when the toroidal current was lowered to $70 \mathrm{kA}$, ORMAK was operated $^{2}$ with neutral beam injection power ( $\left.340 \mathrm{~kW}\right)$ greater than ohmic heating power ( $100 \mathrm{~kW}$ ), again with no fundamental change in the stability or normal energy confinement of the plasma. At low density $\left(\bar{n}_{e} \simeq 2 \times 10^{13}\right.$ $\left.\mathrm{cm}^{-3}\right)$ and reduced impurity concentration $\left(z_{\text {eff }} \sim 3\right)$, significant electron 
heating ( $\mathrm{T}_{\text {eo }}$ from $0.3 \mathrm{keV}$ to $0.75 \mathrm{keV}$ ) by neutral beam injection was demonstrated in addition to ion heating ( $\mathrm{T}_{\text {io }}$ from $0.2 \mathrm{keV}$ to $0.7 \mathrm{keV}$ ). Electron heating was also observed in high current discharges. Heating by neutral beam injection was found to be equivalent to ohmic heating. Also, it was demonstrated ${ }^{1,3}$ that neutral beam injection could be used to raise the ion temperatures to $1.8 \mathrm{keV}$.

With this in mind, the ISX-B experiment under construction at Oak Ridge National Laboratory is designed to test the beta limits predicted for the onset of large scale instabilities ${ }^{4-6}$ as described below. Massive amounts of neutral beam power (from $1.8 \mathrm{MW}$ to $3.0 \mathrm{MW}$ ) will be injected into a moderately small volume of plasma $\left(R_{0}=92 \mathrm{~cm}, a=26 \mathrm{~cm}\right.$, $1 \leqslant \mathrm{~b} / \mathrm{a} \leqslant 1.9,1.2 \leqslant$ plasma volume $\leqslant 2.3 \mathrm{~m}^{3}$ ) in order to achieve an input power density of up to $1.5 \mathrm{~W} / \mathrm{cm}^{3}$ for up to $200 \mathrm{msec}$. The low toroidal magnetic field $(\leqslant 18 \mathrm{kG})$ is compatible with the $40-\mathrm{keV}$ injection energy and is suitable for achieving average beta values up to several percent. The flexible poloidal field design can change the shape of the plasma from circular to elongated $(b / a \leqslant 1.9)$ to $D$-shaped and is designed to accommodate the rapidly heated plasma. In addition, the ISX series of experiments are relatively easy to change (with their split toroidal field coil design), and they are coupled to a large number of diagnostics.

A number of questions must be answered by the experiments as tokamak heating is increased.

(1) What is the effect of ballooning modes as the plasma beta is increased beyond a few percent? Can the predicted instabilities ${ }^{4-6}$ be controlled?

(2) As the injection power becomes much larger than ohmic power, will the quality of the plasma deteriorate? Will there be more impurities? Will the energy confinement time decrease?

(3) "How fast must the plasma be heated to make an effective test of the flux conserving tokamak (FCT) concept, 7-10 and what happens when the magnetic fluxes diffuse?

(4) Do we have adequate control of the equilibrium and axisymerric stability of the plasma during rapid heating?

The ISX-B and PDX experiments are specifically designed to answer most of these questions. 


\section{MHD INSTABILITY COMPUTATIONS}

The Oak Ridge initial value MHD computer code has been used for several years to study the linear and nonlinear evolution of large scale instabilities in toroidal geometry. ${ }^{11}$ Late in 1976, the code was modified to accept axisymmetric equilibria with arbitrary shape ${ }^{4}$ such as the flux conserving high- $\beta$ equilibria computed by Dory and Peng. ${ }^{9}$ In a D-shaped plasma with modest elongation $(b / a=1.6)$, large aspect ratio (Asp $=4.0$ ) and $q_{\text {edge }} / q_{\text {axis }}=3.3$, it was found ${ }^{4}$ that a large scale instability set in when the volume-averaged beta was raised above 4.5\%. In Figs. 1-3 of this report, results are presented for a circular toroidal plasma with lower aspect ratio (Asp $=3.1$ ) and a more peaked current profile ( $\left.q_{\text {edge }} / q_{\text {axis }}=4.5\right)$.

In Fig. 1 it can be seen that a striking change occurs in the growth rate curve as the poloidal beta $\left[\right.$ or $\left.\beta_{J} \equiv\langle p\rangle /\left(\phi d l \cdot B_{p o l} / \phi d l\right)^{2} / 2 \mu_{0}\right]$ is raised until it is comparable to the aspect ratio. As suggested by the Lausanne group, 12 the growth rate curve seems to have two components. In addition to the part that drops to a marginal point near $\mathrm{q}_{\text {axis }}=1$, there is an extended tail that rapidly moves the marginal point out to large $q$ values as $\beta_{p o l}$ is raised. This rapid change in the marginal point as a function of $q_{\text {axis }}$ is a characteristic of ballooning modes driven by pressure gradients and toroidal curvature at high poloidal beta.

Going along with this change in the growth rate curve is a change in the structure of the inotabilitice ac illustrated in Fig. 2. For three values of the equilibrium poloidal beta, level contours are shown for the perturbed pressure in a cross section of the toroid associated with that instability near the marginal point ( $q_{\text {axis }}$ and $\gamma$ specified). Each of these instabilities is helically twisted around the toroid with toroidal mode number $n=1$. The instability shown in the top frame is an ordinary internal $\mathrm{m}=1$ kink mode which dominates all such low- $\beta$ plasmas below $\mathrm{q}_{\text {axis }} \approx 1$. However, as the poloidal beta is raised, as in the middle and lower figures, the strongest part of the instability shifts toward the outer edge of the toroid and additional structure appears from the inner edge. The evident higher poloidal mode numbers 
are due to resonance on flux surfaces with higher $q$ value. However, if one were to follow the perturbed pressure or any perturbation variable along an equilibrium magnetic field line, the perturbation would be strongest at the outer edge of the toroid and would be nearly vanishing at the inner edge. This is characteristic of ballooning modes.

In Fig. 3, the same information given in Fig. 1 is presented in a different way. A level contour of constant growth rate near the marginal stability point is plotted on the $\left(\langle\beta\rangle, q_{\text {axis }}\right.$ ) plane. Poloidal beta is increasing from left to right along the curve. As the poloidal beta is increased, it can be seen that there is a maximum marginally stable beta which is reached when the internal $\mathrm{m}=1 \mathrm{kink}$ mode abruptly changes into a ballooning mode with poloidal harmonics $m>1$. This kind of curve is especially characteristic of ballooning modes with $n \gg 1.6$

The sequence of equilibria used in this study was computed by $\mathrm{Y}-\mathrm{K}$. M. Peng. At $\mathrm{q}_{\text {axis }}=1$, the equilibria are a flux conserving sequence in which the $q(\psi)$ profile is held fixed while the pressure profile is raised. From three members of this flux conserving sequence, the growth rate curves are produced by scaling the equilibria

$$
\begin{aligned}
& \underset{\text { now }}{\mathrm{B}_{\text {nol }}}=\mathrm{SB}_{\text {pol }} \text { old } \\
& P_{\text {new }}=s^{2} P_{\text {old }} \\
& {\left[\left(R B_{\phi}\right)^{2} \text { edge }-\left(R B_{\phi}\right)^{2}\right]=S^{2}\left[\left(R B_{\phi}\right)_{\text {edge }}^{2}-\left(R B_{\phi}\right)^{2}\right] \text { old },} \\
& q_{\text {new }}=q \sqrt{\left(1-s^{2}\right)\left(R B_{\phi}\right)_{\text {edge }}^{2}+s^{2}\left(R B_{\phi}\right)^{2}} /\left.S R B_{\phi}\right|_{o l d} \text {, }
\end{aligned}
$$

where $\mathrm{S}$ is a scale factor. This scaling holds the geometry and poloidal beta fixed, but it can be seen that the q profile is changed. 


\section{CONCLUDING REMARKS}

In comparing this study with other research in the fleld, it becomes evident that ballooning modes are a striking new instability phenomenon at high poloidal beta. The marginal stability condition for ballooning modes depends on the plasma shape. They are more stable in a D-shaped plasma with low aspect ratio. The combination of a broad current profile and a wa11 $1^{13}$ also provides higher stable beta confinement. By analogy with the Rayleigh-Taylor instability, it is expected that viscosity 14 and finite Larmor radius effects ${ }^{15}$ will allow still higher beta before the unstable plasma breaks into the toroidal analogue of Bénard convection cells and confinement deteriorates.

\section{ACKNOWLEDGMENTS}

I am particularly grateful for the many helpful suggestions from D. J. Sigmar, D. B. Nelson, and Y-K. M. Peng.

\section{REFERENCES}

1. L. A. Berry et al., Plasma Physics and Controlzed Nuclear Fusion Research 1976, Vol. 1, pp. 49-68, Berchtesgaden, 1976.

2. M. Murakami et a1., 8th European Conf. on Controlled Fusion and PZasma Physics, Vol. 1, p. 22 Prague, 1977.

3. Equipe TFR, Plasma Physics and Controlled Nuclear Fusion Research 1976, V̄o1. 1, pp. 69-84, Berchtesgaden, 1976.

4. G. Bateman and Y-K. M. Peng, Phys. Rev. Lett. 38, 829-832 (1977).

5. A. M. M. Todd et al., Phys. Rev. Lett. 38, 826-829 (1977).

6. D. Dobrott et a1., Phys. Rev. Lett. 39, 943-946 (1977).

7. J. F. Clarke, High Beta Flux-Conserving Tokamaks, ORNL/TM-5429 (June 1976).

8. J. F. Clarke and D. J. Sigmar, Phys. Rev. Lett 38, 70-74 (1977).

9. R. A. Dory and Y-K. M. Peng, Nucl. Fusion 17, 21-31 (1977).

1.0. J. D. Callen et al., Plasma Physics and Controlled Nuclear Fusion Research 1976, Vol. 2, pp. 369-384, Berchtesgaden, 1976. 
11. W. Schneider and G. Bateman, Plasma Physics and Controlzed Nuclear Fusion Research 1974, Vo1. 1, pp. 429-438, Tokyo, 1974.

12. D. Berger, R. Gruber, and F. Troyon, "Effects of Current Peaking on Ideal MHD Stability," to be published in Phys. Rev. Lett.

13. R. A. Dory et al., 8th European Conf. on Controlled Fusion and Plasma Physics, Vol. 1, p. 69, Prague, 1977.

14. R. Y. Dagazian and R. B. Paris, Phys. Fluids 20, 917-927 (1977).

15. M. S. Chu (General Atomic), private communication, 1977. 
ORNL/DWG/FED - 77447

INSTABILITY GROWTH RATES FOR FCT EQUILIBRIUM

WITH CIRCULAR CROSS SECTION

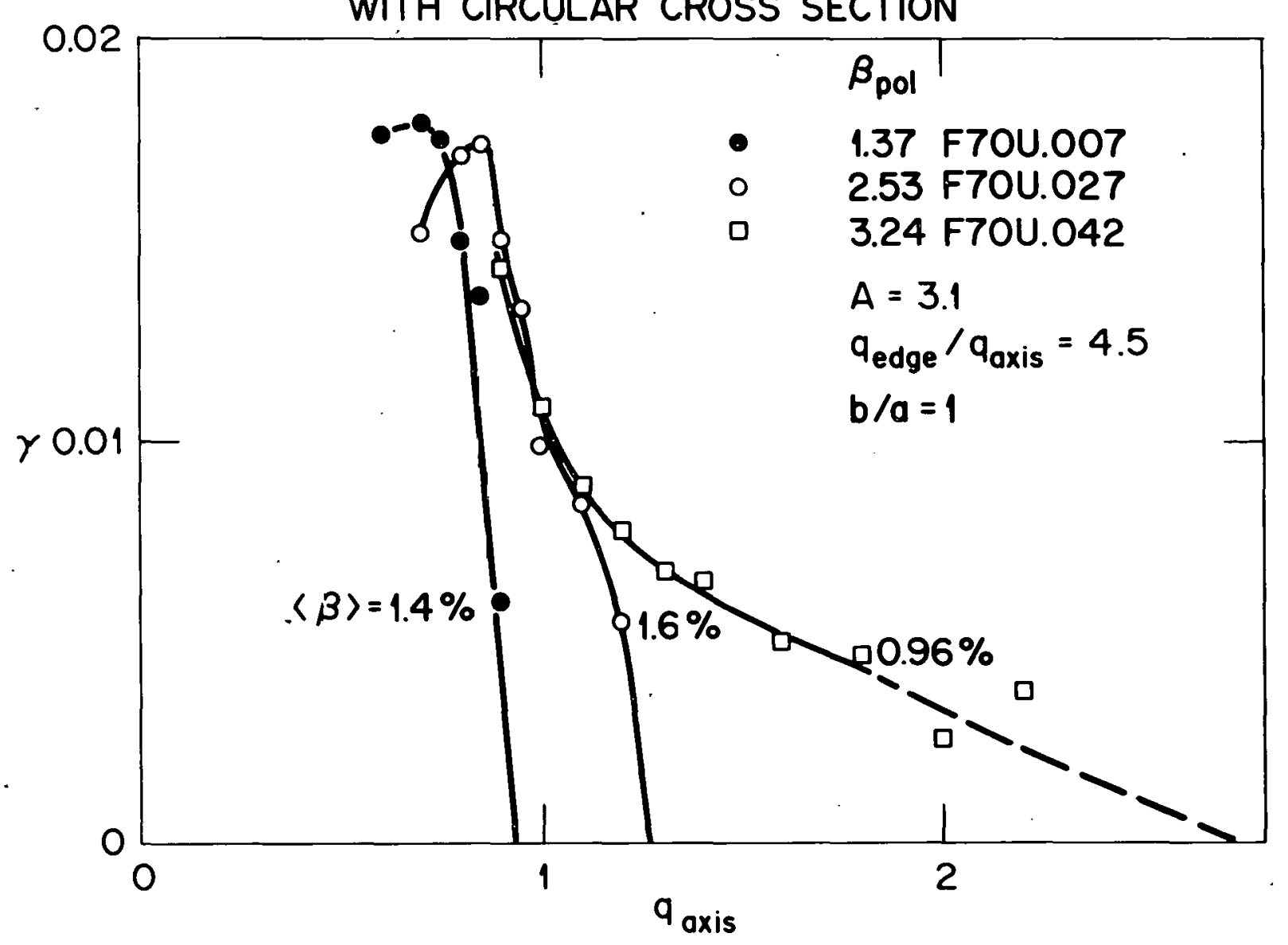

Fig. 1. Instability growth rates for FCT equilibria with circular cross section. 
ORNL/DWG/FED $\cdot 77426$

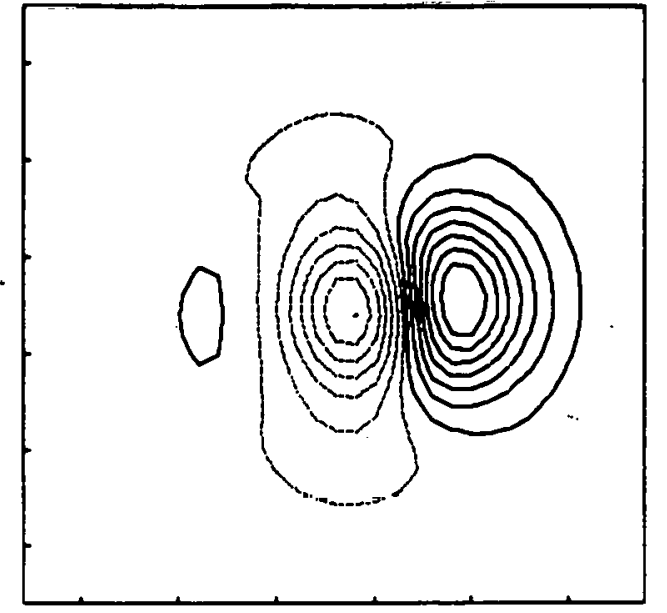

PERTURBED PRESSURE

FOR A LIMEAR MTD

INSTABILITY

$\theta_{\text {Central }}=0.9$

BETA POL $=1.37$

BETA AVE $=1.4 \%$

$A S P=3.1$

$N=1$

$r=0,006$

RGB104FEB

F70U.007

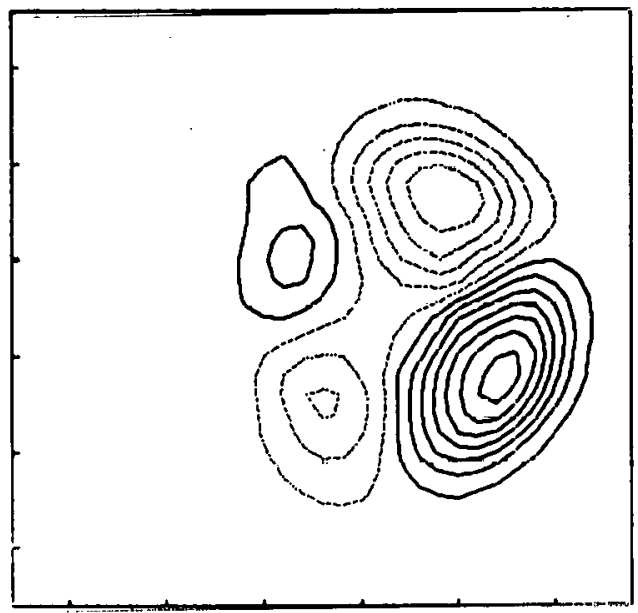

$Q_{\text {CEMTRAL }}=1.2$

BETA POL $=2.53$

BETA AVE $=1.6 \%$

$\gamma=0.0055$

RGB911FEB

F70U.027

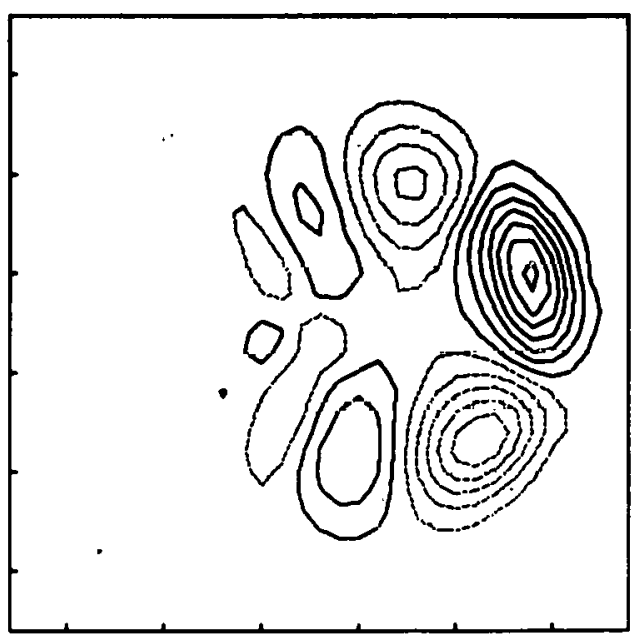

$\theta_{\text {central }}=2.2$

BETA POL $=3.24$

BETA AVE $=0.65 \%$

$r=0.0037$

RGB225FEB

F7011.042

$34 \times 35$ GRID

BATEMAN PENG

Fig. 2. Perturbed pressure contours for instabilities near the marginal point as poloidal beta is increased. 
ORNL/DWG / FED - 77448

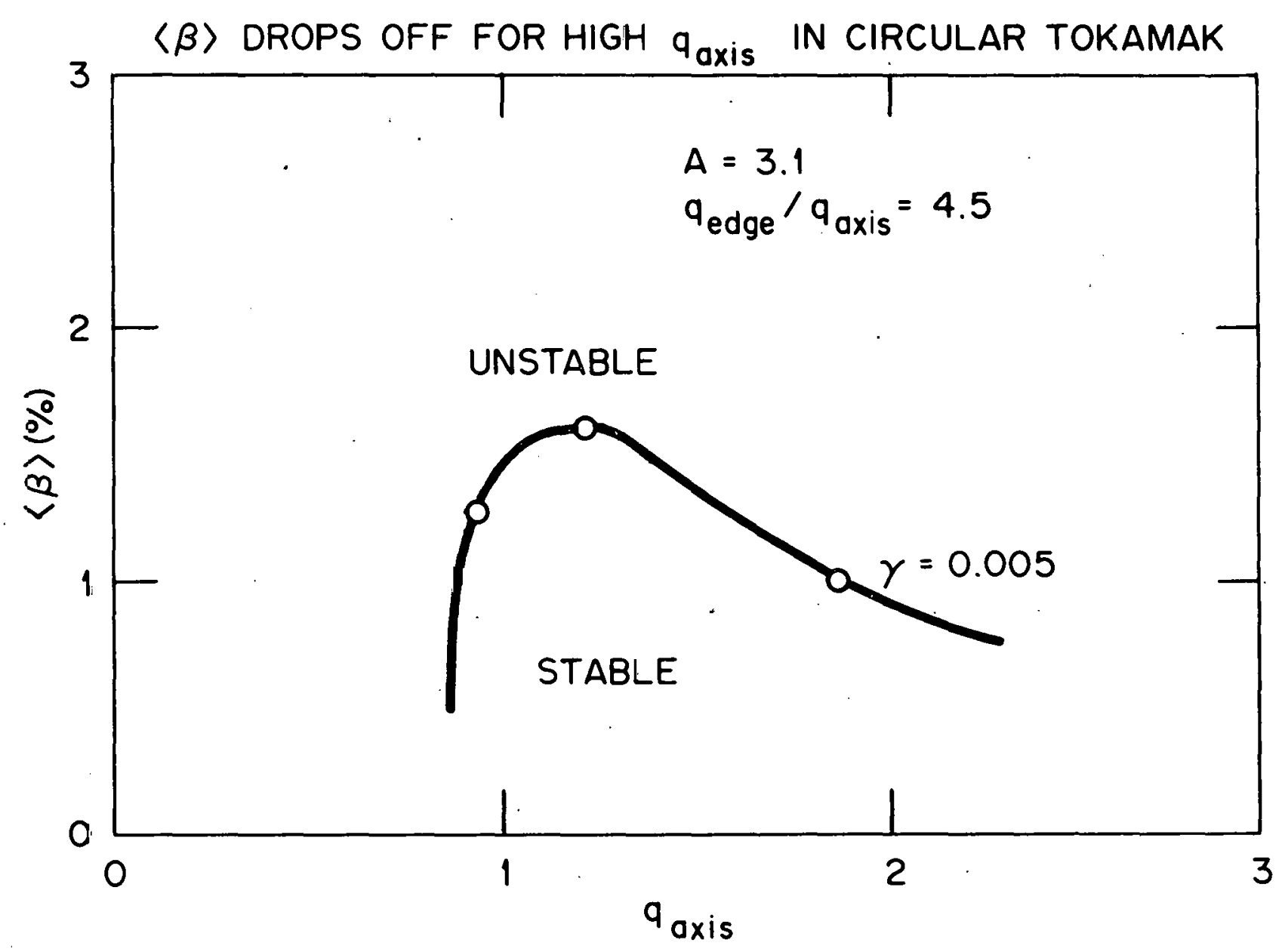

Fig. 3. Volume-averaged beta as a function of $q$ value at the magnetic axis. Poloidal beta increases along the curve from left to right. 
FUNDAMENTAL TIME SCALES FOR FLUX CONSERVING TOKAMAK

HEATING AND CERTAIN GLOBAL FCT EQUILIBRIUM PROPERTIES

\author{
D. J. Sigmar *
}

ABSTRACT

Because the existence of high- $\beta$ flux conserving equilibria has been established, it becomes important to analyze the accessibility of these equilibria via auxiliary heating, to discuss the resistive decay of the safety factor profile, and to extend the virial theory to noncircular plasma cross sections.

\title{
1. TIME SCALES FOR FLUX CONSERVATION
}

There is a fundamental difference between ohmically heated and beam heated tokamaks. In the former, the energy confinement time, ' $E$ ' has to equal the heating time, $\tau_{h}$, the poloidal beta is transport limited to $\beta_{p} \leqslant R / a$, and flux diffusion is in equilibrium with the pressure rise. In the latter, $\tau_{h}$ can in principle be decoupled from $\tau_{E}$, $\beta_{p}>R / a$ is possible without encountering an MHD equilibrium limit, and flux diffusion is much slower than the beam driven pressure rise. Let us pursue these ideas for a specific next generation tokamak, the ISX-B at ORNL.

The primary objective of ISX-B is to test the effects of strong beam heating $\left(\mathrm{P}_{\mathrm{b}} / \mathrm{P}_{\mathrm{OH}} \leqslant 10\right)$ in an elongated tokamak plasma. Theoretical estimates of MHD instability limits and of the transport properties of a low field, moderate size plasma such as ISX-B arrive at a few percent $B$. With an aspect ratio $A=3.5$ and expecting $q^{2} \sim 0(10)$ one obtains from the naive formula

$B_{p}-q^{2} \Lambda^{2} B \sim 10 \times 12.5 \times \beta>A$, commonly called the high- $\beta$ regime. Numerical calculations yield similar results for $\beta_{\mathrm{p}}$.

\footnotetext{
On leave of absence from Massachusetts Institute of Technology.
} 
With $P_{b} \leqslant 3 \mathrm{MW}$, the heating time, $\tau_{h}=p /\left(P_{O H}+P_{b}\right)$, is expected to fall below the poloidal skin time, $\tau_{s}=4 \pi a^{2} / n_{\|} c^{2}$, so that from

$\frac{\tau_{h}}{\tau_{s}} \simeq \frac{{ }_{p}}{8} \frac{1}{1+P_{b} / P_{O H}}$

it appears that the plasma is taken from its initial ohmic heating equilibrium with $\beta_{p} \leqslant 1$ to $\beta_{p} \leqslant A$ in less than a skin time. Thus one concludes from a very simple theoretical viewpoint that in ISX-B the stage is set for a flux conserving transition to high- $\beta$ tokamak equilibria.

It is worthwhile to investigate this time ordering in more detail, including the effect of finite energy confinement time $\tau_{E}$ and the delay in heating due to the finite slowing down time $\tau_{f}$. The simplest model for the pressure rise is

$\frac{\partial p}{\partial t}=-\frac{p}{\tau_{E}}+P_{b}\left(1-e^{-t / \tau} f\right)+P_{O H}$

where $\tau_{f}$ is the slowing, down time of the fast injected particles, and $P_{b}$ and $\mathrm{P}_{\mathrm{OH}}$ are the power/volume into the plasma due to beam injection and ohmic heating, respectively. We define $\tau_{E}^{-1}=\kappa / 4 a^{2} n, k$ being the effective perpendicular heat conductivity. [We note from Eq. (1) that only in purely ohmic steady-state discharge does $\tau_{E}$ equal the usual definition $\tau_{E}=$ $\left.\mathrm{p} / \mathrm{P}_{\mathrm{OH}} \cdot\right]$

From the solution of Eq. (1),

$\frac{P(t)}{P(0)}=e^{-t / \tau} E+\frac{{ }^{\tau} E^{P} O H}{p(0)}\left(1-e^{-t / \tau_{E}}\right)+\frac{{ }^{\tau} E^{P} b}{P(0)}\left[\left(1-e^{-t / \tau_{E}}\right)+\frac{e^{-t / \tau_{E}}-e^{-t / \tau_{f}}}{1-\tau_{E} / \tau_{f}}\right]$,

one obtains for the fractional pressure rise at $t=\tau_{E}$

$\frac{\Delta p}{p}=\frac{p\left(\tau_{E}\right)-p(0)}{p(0)}-0.632\left[\frac{\tau_{E}\left(P_{O H}+P_{b}\right)}{p(0)}-1\right]+\frac{\tau_{E} P_{b}}{p(0)}\left(\frac{e^{-1}-e^{-\tau_{E} / \tau_{f}}}{1-\tau_{E} / \tau_{f}}\right)$,

and we recall that for $P_{b}=0,{ }_{E}{ }^{P}{ }_{O H} / p(0)-1=0$. In the desirable limit $\tau_{f} / \tau_{E} \ll 1$, Eq. (3) becomes 
$\frac{\Delta p}{p} \simeq 0.632\left[\frac{{ }_{E}{ }_{E}\left(P_{O H}+P_{b}\right)}{p(0)}-1\right]$,

an expected result, whereas in the opposite limit of poor confinement $\tau_{\mathrm{f}} / \tau_{\mathrm{E}} \gg 1$, there results

$\frac{\Delta p}{p} \simeq 0.632 \frac{\tau_{E}{ }^{P} O H}{p(0)}\left(1+0.582 \frac{\tau_{E}}{\tau_{f}} \frac{P_{b}}{P_{O H}}\right)-0.632$,

indicating that beam heating will not occur unless $\mathrm{P}_{\mathrm{b}} / \mathrm{P}_{\mathrm{OH}}>\left(\tau_{f} / \tau_{E}\right) \times 2.72$. Specifically for the ISX-B parameters, Vol. $=1.23 \times 10^{6} \mathrm{~cm}^{3}$ (for c1rcular cross section), $\mathrm{n}=2 \cdot 10^{13} \mathrm{~cm}^{-3}, \mathrm{I}_{\mathrm{e}}+\mathrm{I}_{1}=0.6 \mathrm{keV}$, and $\tau=8$ msec (a very conservative number). One has $\mathrm{p}(0) / \tau_{\mathrm{E}} \times \mathrm{Vol} .=300 \mathrm{~kW}$, whence it follows from Eq. (4) that to produce a $\Delta p / p$ of 2 in one energy containment time takes $1.26 \mathrm{MW}$, quite within the range of available beam powers. This reconfirms the statement made previously that ISX-B may have the injection power to heat flux conservingly, provided the energy confinement time, $\tau_{E}$, does not strongly deteriorate with high power injection, which ultimately only the experiment can show. (Model dependent transport simulations including trapped ion mode anomalous diffusion and beam driven impurity effects lead to less optimistic predictions at 3 MW of beam power.)

\section{RESISTIVE DECAY OF TIE $\mathrm{q}(\psi)$-TROFILE}

While it appears feasible to conserve flux on the beam heating time scale, flux diffusion will occur on the slower resistive time scale.

Because the classical perpendicular resistivity $n_{\perp}^{\mathrm{cl}}=2 n_{\|}=2 n_{\mathrm{s}}$ in a magnetized plasma, where $n_{s}$ is the Spitzer-resistivity and, judging from anomalously enhanced electron cross-field diffusion, $\eta_{\perp \text { effective }}>\eta_{\perp}$ is possible, it is interesting to find the diffusion coefficient for the decay of $q(\psi, t)$ and its dependence on $\eta_{\|}$and/or $n_{1}$.

Several authors seem to have addressed this question recently. Byrne and Klein ${ }^{l}$ derived the essential ingredients for an equation of the form $\frac{\partial q(\psi, t)}{\partial t}=\frac{\partial}{\partial \psi} n_{\|} k_{1} \frac{\partial\left(q k_{2}\right)}{\partial \psi}$ 
without actually writing it down. Pereversiev et al. derived Eq. (6) precisely but not in an easily accessible paper. ${ }^{2}$ The coefficients $k_{1,2}(\psi)$ are related to the inductance coefficients, $k=\left\langle|\nabla \psi|^{2} / R^{2}\right\rangle$ and $A=\left\langle R^{-2}\right\rangle$. Hirshman ${ }^{3}$ arrived at the more general result

$4 \pi^{2} \frac{\partial q\left(\psi_{1} t\right)}{\partial t}=\frac{\partial}{\partial \psi}\left[V^{\prime}(\psi)<\underline{E} \cdot \underline{B}>\right]$,

where $\underline{E}$ is the electric field, $\underline{B}$ the magnetic field, $V(\psi)$ is the volume inside a flux surface $\psi$, and $<>$ denotes a flux surface average. This result follows solely and simply from Faraday's law and toroidal symmetry, starting with the defining relation for the safety factor

$q(\psi)=\frac{d \Phi}{2 \pi d \psi}=\frac{1}{4 \pi^{2}}\left(R B_{\phi}\right) V^{\prime}(\psi)<R^{-2}>$,

where $R$ is the major radius to a point on the flux surface. The fundamental insight from Eqs. (6) and (7) derives from the fact that only the parallel resistivity enters the flux diffusion time, $\tau_{M} \sim\left(n_{\|}\left\langle|\nabla \psi|^{2}\right\rangle / \psi_{O}^{2}\right)^{-1}$, where $\psi_{0}$ is the total poloidal flux in the plasma column. Because the parallel resistivity in tokamaks appears to be purely classical, this result bodes well for flux conservation in hot large tokamaks unless it turns out that in the reactor regime the re should exist an unforeseen anomalous bootstrap current, driving $\langle\underline{E} \cdot \underline{B}\rangle$ in Eq. (7) or, concomitantly, that the quantities entering the expression for $\tau_{M}$ implicitly are subject to anomalous perpendicular diffusion.

\section{GLOBAL EQUILIBRIUM CHARACTERISTICS OF NONCIRCULAR FLUX CONSERVING TOKAMAKS}

A year ago Clarke and Sigmar $^{4}$ calculated the pressure driven increase of the total plasma current I during the flux conserving heating phase of a tokamak plasma with circular cross section. The unexpected result was that $I \propto p^{+1 / 3}$ (where $\bar{p}$ is the volume averaged pressure) and thus $\beta_{p} \sim p^{-1 / 3} \sim$ $\beta^{1 / 3}$, a radical departure from the usual formula $\beta_{p}=B\left(q^{2} / e^{2}\right)^{p} \sim \bar{p}$. The seeming paradox is resolved when one realizes that in an ohmically heated tokamak the steady-state pressure is proportional to $I^{2}$, whereas in the FCT the pressure rises due to the auxiliary heating, and the current has to 
adjust according to pressure balance and the constraint of flux conservation.

The resulting relatively smaller value of $\beta_{p}$, achieved at a certain value of $\beta$ and at the same value of $q(a)$ [since $q(\psi)$ is frozen in] as in the initial low- $\beta$ state, suggests improved stability behavior of those pressure driven modes whose threshold depends on $\beta_{p}$, besides postponing equilibrium limitations which (although not operative on the flux conserving time scale) may threaten the confinement on a longer time scale. It is therefore useful to rework the calculation of Ref. 4 for an elliptical minor cross-section plasma. This has been initiated by Mizoguchi and Kammash, 5 whose first results we will briefly report here.

Following Ref. 4, an elliptical flux nodel is assumed as

$a^{2} \frac{\psi}{\psi_{0}}=\left(R-R_{\psi}\right)^{2}+k(\psi) z^{2}$,

where $R_{\psi}$ is the center of the individual flux contour $\psi=$ constant, $\psi_{0}$ is the total poloidal flux in the plasma, and $k=a^{2} / b^{2}$ describes the (variable) elongation. Then the poloidal field is given by

$\mathrm{RB}_{\mathrm{p}}=\frac{2 \psi_{\mathrm{o}}}{\mathrm{a}} \frac{\sqrt{(1-k) \cos ^{2} \theta+k}}{1+\mathrm{d} \cos \theta}$

where $\mathrm{d}=2 \psi_{0} / \mathrm{a} \mathrm{dR}_{\psi} / \mathrm{d} \psi$ measures the Shafranov-Shift.

Generalizing the virial theory of Ref. 4 to include the elliptical

terms in $B_{p}$, Mizoguchi and Kammash find for the poloidal beta, in the high$\beta$ (i.e., $\beta \sim a / R$ ) limit,

$B_{p}=\left(\frac{R}{a}\right)^{2 / 3}\left[\kappa^{1 / 3}\left(\frac{1+\kappa}{2}\right)^{2 / 3}\right]\left(\bar{\beta}_{p}\right)^{1 / 3}$

where $\bar{B}_{\mathrm{p}} \equiv \int \mathrm{pdV} / \pi \mathrm{RI}^{2}$ in measures the pressure, normalized by the square of the initial (1ow- $\beta$ ) current. For a $2: 1$ elongation the factor in brackets [Eq. (9)] equals 0.46 , showing a marked additional reduction of $\beta_{p}$ due to elliptical geometry, besides the flux conserving reduction derived in Ref. 4 for the circular plasma cross section. Thus it appears possible to produce elongated high- $\beta$ plasmas with $\beta_{p} \geq 1$. 


\section{REFERENCES}

1. R. N. Byrne and H. Klein, J. Comput. Phys., in press.

2. G. V. Pereversiev, V. D. Shafranov, and L. E. Zakharov, paper given at the IAEA-sponsored Tokamak Theory Meeting in Trieste, April 1977.

3. S. P. Hirshman (Princeton Plasma Physics Laboratory), private communication, 1977.

4. J. F. Clarke and D. J. Sigmar, Phys. Rev. Lett. 38,70 (1977).

5. T. Mizoguchi and T. Kammash, to be published. 
INTENSE NEUTRAL BEAM HEATING IN THE ADIABATIC APPROXIMATION

D. B. Nelson

\section{INTRODUCTION}

The economic viability of tokamak fusion reactors improves significantly if $\beta$ can be raised above $5 \%$ to $10 \%$. High powered neutral particle injection makes possible the attainment of such $\beta$ values if the correspunding equilibria exist, are dynamically accessible, and can be maintained against instabilities and transport. Early analytic work seemed to indicate a restrictive equilibrium constraint, $\beta_{\text {pol }}<1 / \varepsilon$ or $\beta<\varepsilon / q^{2}$, with $\varepsilon$ the inverse aspect ratio (typically $1 / 3$ to $1 / 5$ ) and $q$ the safety factor at the wall (typically 3 to 5 ). 1 The physical process which limits $\beta$ was the appearance of a poloidal fie1d null (stagnation point) at the inside edge of the plasma. However, if energy is deposited on a time scale which is rapid compared with the resistive skin time, the magnetic flux remains frozen. The plasma then evolves as a flux conserving tokamak (FCT), and a stagnation point cannot move into the plasma. ${ }^{2}$ Recent calculations have exploited the FCT concept to produce equilibria with $\beta$ exceeding $30 \%$, considerably above the supposed limit. ${ }^{3}$ These calculations do not demonstrate the dynamic accessibility of high- $\beta$ equilibria; in fact, the authors were only able to calculate FCT equilibria over a limited range of parameters. If this were due to nonexistence of equilibrium, the initial state and heat deposition profile would have to be carefully tailored to achieve success.

This paper exhibits a simple method for following the dynamic cvolution of the plasma under neutral beam heating. While the method used is also being applied to more general transport calculations, for these results it is assumed that the heating is rapid compared with resistive diffusion or cross field heat conductivity. Thus the plasma evolves adiabatically, i.e., according to the ideal MHD equations. It is found that high- $\beta$ states can be attalned with a wide variety of initial conditions and heating profiles. 


\section{EQUATIONS OF MOTION}

The basic equations used are the single fluid ideal MHD equations with a particle source and an energy source. Viscous effects, resistivity, and cross field thermal conductivity are neglected in accordance with the assumed time scale:

$\frac{d \rho}{d t}+\rho \nabla \cdot u=\sigma$

$\rho \frac{d u}{d t}+\nabla p=J \times B$

$\rho \frac{\mathrm{de}}{\mathrm{dt}}+\mathrm{p} \nabla \cdot \mathrm{u}=\nabla \cdot\left[\frac{\mathrm{K}_{\|}}{\mathrm{B}^{2}} \mathrm{~B}(\mathrm{~B} \cdot \nabla \mathrm{T})\right]+\mathrm{Q}$,

$\frac{\partial B}{\partial t}=\nabla \times(u \times B)$

$\mathrm{J}=\nabla \times \mathrm{B}, \quad \nabla \cdot \mathrm{B}=0$.

Here $d / d t=\partial / \partial t+u \cdot \nabla$ is the Lagrangian (convective) time derivative, $\rho$ is the mass density, $u$ is fluid velocity, $\sigma$ is the mass source per unit volume per unit time, $\mathrm{p}$ is pressure, $\mathrm{J}$ is current density, $\mathrm{B}$ is the. magnetic field, $T$ is the temperature, $e$ is internal energy per unit mass, $\kappa_{\|}$is the parallel thermal conductivity, and $Q$ is the energy source per unit volume per unit time.

We are interested in processes which are slow compared with MHD waves and parallel heat conductivity. Simple dimensional analysis of the momentum Eq. (2) shows that

$\left|\rho \frac{d u}{d t}\right| /|\mathrm{J} \times \mathrm{B}| \approx \mathrm{u}^{2} / \mathrm{v}_{\mathrm{A}}^{2}, \quad \mathrm{v}_{\mathrm{A}}^{2}=\mathrm{B}^{2} / \rho$

So if $u \ll v_{A}$ we can neglect the inertial term in Eq. (2) and the plasma remains in equilibrium: 
$\nabla p=J \times B$

(This result can also be obtained using a formal expansion procedure.) 4-6 $^{-6}$ Similarly, the Appendix shows that with large $\kappa_{\|}, T$ and $\rho$ are constant to lowest order on magnetic surfaces and the heat conductivity term in Eq. (3) can be omitted.

To complete the system we take as equation of state the perfect gas law:

$p=\left(r^{p}-r^{v}\right) \rho T$

Then using the relations

$e=c_{v} T, e=p / \rho(\gamma-1)$, and $\gamma=c_{p} / r_{v}>1$,

we can eliminate e from Eq. (3) in favor of $\mathrm{p}$ :

$\frac{d p}{d t}+\gamma p \nabla \cdot u=(\gamma-1) Q+\frac{p}{\rho} r$.

For axisymnetric geometry appropriate to a tokamak, the magnetic field can be written as

$B=\nabla \zeta \times \nabla \psi+f(\psi) \nabla \zeta$,

where $\zeta$ is the ignorable toroidal angle and $\psi$ is the poloital flux function. The equilibrium equation then becomes Stokes' equation ${ }^{7}$

$\Delta * \psi=-r^{\ddot{2}} \mathrm{dp} / \mathrm{d} \psi-\mathbf{f} \mathrm{df} / \mathrm{d} \psi$

with $\Delta^{*} \psi=\partial^{2} / \partial z^{2}+\partial^{2} / \partial r^{2}-(1 / r) \partial / \partial r$. The functions $\psi$ and $f$ satisfy time dependent equations which can be deduced from Faraday's 1aw, Eq. (4):

$\frac{\partial \psi}{\partial t}+u \cdot \nabla \psi=-c(t)$, 
$\frac{1}{r^{2}} \frac{\partial f}{\partial t}+\nabla \cdot\left(f \frac{u}{r^{2}}-B \frac{u_{\zeta}}{r}\right)=0$,

where $c(t)$ is an integration constant related to the applied electric field. ${ }^{4}$

\section{FLUX SURFACE AVERAGED EQUATIONS}

To determine the adiabatic response of a tokamak to neutral beam heating, only the component of velocity which is normal to the flux surfaces is required. The tangential components are substantial and serve to maintain equilibrium, but they can be eliminated from the equations by flux surface averaging. This procedure results in equations of motion which depend on only one space variable. To carry it through we introduce as a variable the volume, $v$, contained within a given flux surface. The surface average $\langle\phi\rangle$ is defined by

$\langle\phi\rangle=\int \phi \mathrm{dS} /|\nabla \mathrm{v}|$

where dS is the surface element on a given flux surface. Note that this average is normalized, i.e., $\langle 1\rangle$ is unity since

$$
\int_{0}^{v_{0}} \phi d^{3} x=\int_{0}^{v_{0}}\langle\phi\rangle d v .
$$

To surface average the equilibrium equation, one uses the fact that $\Delta^{*} \psi / \mathrm{r}^{2}=\nabla \cdot\left(\nabla \psi / \mathrm{r}^{2}\right)$. Then, integrating over a volume shell between $\mathrm{v}$ and $v+d v$ and using the divergence theorem, one finds

$\psi^{\prime}\left(K \psi^{\prime}\right)^{\prime}=-p^{\prime}-\operatorname{Aff}$,

where

$\mathrm{K}=\left\langle|\nabla \mathrm{v}|^{2} / \mathrm{r}^{2}\right\rangle, \quad \mathrm{A}=\left\langle 1 / \mathrm{r}^{2}\right\rangle, \quad,=\frac{\partial}{\partial \mathrm{v}}$. 
To average the time dependent equations we recall the calculus formula for the time derivative of an integral over a moving volume:

$\frac{d}{d t} \int_{0}^{v(r, z, t)} \phi(r, z, t) d^{3} x=\int_{0}^{v} \frac{\partial \phi}{\partial t} d^{3} x+\S \phi w \cdot d S$,

where $w$ is defined by

$\frac{\partial v}{\partial t}+w \cdot \nabla v=0$

We then define the partial derivatives for functions of $v$ and $t$ :

$\psi_{L}=\partial \psi(v, t) / \partial t . \quad \psi^{\prime}=\partial \psi(v, t) / \partial v$,

and note that

$\frac{d}{d t} \int_{0}^{v_{0}} \phi(r, z, t) d^{3} x=\int_{0}^{v_{0}}\langle\phi\rangle_{t} d v$,

$\left.\frac{\partial v}{\partial t}\right|_{r, z}=\frac{1}{\psi}\left(\left.\frac{\partial \psi}{\partial t}\right|_{r, z} \quad \psi_{t}\right)$

Using Eqs. (14), (15), and (16) one can derive the formulas

$\frac{d}{d t} \int_{0}^{v_{0}} \phi d^{3} x=\int_{0}^{v_{0}} \frac{\partial \phi}{\partial t} d^{3} x+\S \frac{\phi}{\psi} \cdot\left(\psi_{t}-\frac{\partial \psi}{\partial t}\right) d \zeta /|\nabla v|$,

$\langle\phi\rangle_{t}=\left\langle\frac{\partial \phi}{\partial t}\right\rangle+\left\langle\frac{\phi}{\psi^{\prime}}\left(\psi_{t}-\frac{\partial \psi}{\partial t}\right)\right\rangle^{\prime}$.

As special cases $\phi=1$ yields $\langle\partial v / \partial t\rangle=0$, and $\phi=\psi(v, t)$ gives

$\langle\partial \psi / \partial t\rangle=\langle\psi\rangle_{t}$ 
In the Appendix it is shown that for large $\kappa_{\|}$; only the lowest order temperature and density, which are constant on a surface, appear in the surface-averaged equations. Integrating Eqs. (1), (8), and (11) over a volume shell of thickness $\delta v$, and using the divergence theorem gives

$\rho_{t}+(\rho U)^{\prime}=\langle\sigma\rangle$

$p_{t}+\gamma p U^{\prime}+p^{\prime} U=(\gamma-1)\langle Q\rangle+p<\sigma>/ \rho$,

$\psi_{t}+U \psi^{\prime}=-c(t)$

where $U=\langle u \cdot \nabla v\rangle$. Integrating Eq. (12) over the volume within a flux surface gives an equation for the toroidal flux:

$X_{t}+U X^{\prime}=-c_{1}(t)$

where

$x=\int_{0}^{v}\left(f / r^{2}\right) d^{3} x+x(0), \quad x^{\prime}=f A$,

and $c_{1}(t)$ is an integration constant related to $x(0)$. In summary, the evolution of the plasma is determined by time dependent equations for $\rho$, $p, \psi$, and $x$, the averaged equilibrium equation which implicitly determines $U$ and the two-dimensional equilibrium equation which determines $A$ and $K$ :

$\rho_{t}+(\rho U)^{\prime}=\langle\sigma\rangle$

$\left.p_{t}+\gamma p U^{\prime}+p^{\prime} U=(\gamma-1)<Q\right\rangle+p<\sigma>/ \rho$

$\psi_{t}+U \psi^{\prime}=-c(t)$

$X_{t}+U X^{\prime}=-c_{1}(t)$

$\psi^{\prime}\left(K \psi^{\prime}\right)^{\prime}=-p^{\prime}-A f f^{\prime}$,

$\psi^{\prime} \Delta^{*} \psi=-r^{2} p^{i}-f t^{i}$ 
4. POIOIDAL FLUX AS INDEPENDENT VARIABLE

Although the set of equations given above can be used for some calculations, e.g., at low $\beta$, solving for the velocity is awkward. This difficulty can be overcome by changing the independent varlable from $v$ to $\psi$. To proceed we define the derivatives for functions $\phi(\psi, t)$ :

$\frac{\mathrm{d} \phi}{\mathrm{dt}}=\left.\frac{\partial \phi}{\partial t}\right|_{\psi}, \quad \dot{\phi}=\left.\frac{\partial \phi}{\partial \psi}\right|_{t}$,

and note that because $\phi(v, t)=\phi[v(\psi, t), t]$, we can write

$\phi_{t}+U \phi^{\prime}=\mathrm{d} \phi / \mathrm{dt}-\mathrm{c}(\mathrm{t}) \dot{\phi}$

In addition, the right choice of dependent variables simplifies the calculation. We introduce $\xi, \mu, \nu$ by

$\xi=\rho / \psi^{\prime}$,

$\mu=\mathrm{p}\left(\psi^{\prime}\right)^{-\gamma}$,

$v=d x / d \psi$

These variables are related to the mass, entropy, and toroldal flux contained between neighboring flux surfaces. Then an easy calculation shows that $(\xi, \mu, \nu)$ satisfy the equations

$\frac{1}{\xi} \frac{\mathrm{d} \xi}{\mathrm{dt}}=\frac{r \cdot \sigma \cdot}{\rho}+c(t) \frac{\dot{\xi}}{\xi}$

$\frac{1}{\mu} \frac{d \mu}{d t}=(\gamma-1) \frac{\langle Q>}{p}+\frac{\langle\sigma\rangle}{\rho}+c(t) \frac{\dot{\mu}}{\mu}$,

$\frac{1}{v} \frac{d v}{d t}=c(t) \frac{\dot{v}}{v}$. 
If $\psi$ remains constant at the magnetic axis, as is appropriate for adiabatic processes, then $c(t)$ vanishes, and Eqs (22) have a simple interpretation as conservation relations. For then $\nu(\psi)$ remains constant in time, and if $\sigma$ and $Q$ are zero, $\xi(\psi)$ and $\mu(\psi)$ are also time independent. These are just the adiabatic constraints on $f$ lux, density, and pressure.

Eqs (22) are advanced in time, along with the equilibrium equation, using the method of Generalized Differential Equations. ${ }^{6}$ An initial equilibrium is computed with prescribed $\mu(\psi), \nu(\psi), \psi$ axis, $\psi$ edge, and the flux from external coils. Then $\xi$ and $\mu$ are advanced in time using $\dot{v}(\psi)$ from the equilibrium solution as well as prescribed $\sigma$ and $Q$ profiles. A new equilibrium is computed using the updated $\xi(\psi)$ and $\mu(\psi)$ to obtain a new $\dot{v}(\psi)$, and the calculation proceeds alternating between one-dimensional heating and two-dimensional equilibrium calculations.

\section{APPLICATIONS}

We have studied the adiabatic heating of tokamaks with a wide variety of initial conditions and prescribed heating profiles. Examples of the calculation are shown in Figs. 1-4. In these cases we studied the change in the plasma evolution as $Q$, representing neutral beam heating, was varied from being peaked on the magnetic axis to being peaked away from the axis. (The mass source $\sigma$ was zero in these cases.) Among the equations of interest were: 1) Does equilibrium continue to exist for varying Q? 2) How does $Q$ affect the shift of the magnetic axis? 3) What is the resultant plasma current profile? 4) Must external toroidal and poloidal fields be carefully programed to maintain equilibrium? Figure 1 shows the initial pressure and safety factor profiles as well as the final pressure profiles for two choices of $Q(\psi)$. (Note that the safety factor, $q(\psi)$, is equal to $\nu(\psi) / 4 \pi^{2}$.) For simplicity the calculations did not include any time variation in $Q$. The heating profiles for these two cases are also shown in Fig, 1. In the first case $Q(\psi)$ peaked strongly on axis, whereas in the second case, which modeled the failure of the beam to penetrate, $Q$ peaked off axis. (We have made several additional runs with intermediate amounts of peaking.) Not surprisingly, the pressure evolution follows the heating profile since no transport effects are included. 
Figure 2 shows the evolution of the flux surfaces in the two cases, from an initial $\bar{\beta}$ (average $\beta$ ) of $2 \%$ to a final $\bar{\beta}$ of $15 \%$ in both cases. It can be seen that in the second case the flux contours are considerably distorted, and the magnetic axis has shifted inward in contrast to the customary outward shift exhibited by the first case. Figure 3 shows the pressure and. toroidal current density on the equatorial plane for the initial state and the two final states. In the high- $\beta$ equilibria, $J_{\zeta}$ is largest where $\mathrm{p}^{\prime}$ is largest, showing the presence of strong diamagnetic currents.

The contribution to the current density from the diamagnetic function, $f(\psi)=\mathrm{rB}_{\zeta}$, is particularly interesting for the case where the heating peaks off axis. Figure 4 shows that the final state for this case has both paramagnetic regions, where $f$ is increased over that of the vacuum field, and diamagnetic regions, where it is depressed. If the heating peaks on axis, Fig. 4 shows that the plasma is diamagnetic everywhere. Since paramagnetism in a plasma is associated with force-free currents $(J \times B$ is small, hence $\nabla p$ is small), the ability of neutral beam heating to create regions of large force-free currents is of some interest. This is because force-free currents have been found to influence favorably the stability of plasmas to internal ballooning modes. ${ }^{8}$ of course, one should not infer from this that hollow pressure profiles are stah1e, The stability of these states has not yet been investigated.

The rise in $f(\psi)$ at the plasma edge as $\beta$ is increased, shown in Fig. 4 , has been observed previously. ${ }^{3}$ Since $f$ is constant in the vacuum region outside the plasma, either the toroidal field at the toroidal field coils must rise in the cases computed, or else a skin current must be produced to support a jump in $f$ at the plasma edge. However, a skin current cannot be maintained in a resistive plasma, and raising the current rapidly in high-inductance toroidal field coils to follow the changing equilibrium would be difficult. Interestingly, equilibrium requirements can be satisfied and a skin current avoided by programming the poloidal field coil system to control the volume and shape of the plasma. No toroidal coil programming is required. This conclusion follows from noting that it is not necessary to drive the toroidal field coils if the flux within them can remain constant. In the adiabatic approximation it is only 
necessary to ensure that the vacuum flux remains constant, because the plasma flux is automatically held fixed. The vacuum flux is given by $x_{v a c}=f_{v a c} \int d v / r^{2}$

with the integral taken over the vacuum. Thus a skin current is avoided and $x_{v a c}$ remains fixed, if $f_{v a c}$ (which may change due to changing plasma shape) can be matched to $f_{\text {plasma }}=\nu \psi^{\prime} / A$. Since $\nu$ is fixed adiabatically, $f_{\text {plasma }}$ is modified by changes in $\psi^{\prime}$ and $A$, both of which can be controlled by the poloidal field coll system. In the cases discussed here the external poloidal flux was adjusted to allow the plasma to expand slightly, reducing the increase in $\psi^{\prime}$ which would occur with fixed boundary as the plasma expands to the outside of the shell. At the same time A increased so: $\psi$ '/A rose only slightly; changing the plasma shape as well as its volume would allow even greater control over $\psi^{\prime} / A$. Since the vacuum volume was thereby reduced, the rise in $f_{\text {plasma }}$ would be just correct to avoid a skin current for a certain coil size. In general, one could measure the toroidal field at the coils and incorporate the information into a poloidal feedback system.

The total toroidal current also rises as the plasma is heated. This is largely due to an increase in the plasma inductance; the total current is proportional to $\mathrm{K} \psi^{\prime}$, both taken at the plasma edge. $\mathrm{K}$, the poloidal inductance, 6,9 increases strongly compared with the small rise in $\psi^{\prime}$ as the plasma is deformed away from approximately circular cross section. If desired, this current rise could be partly programmed by controlling the plasma size and shape. Generally in contrast with present experiments, one will not run FCT plasmas with constant current.

Based on these and other results, we can now answer the questions posed at the beginning of this section: 1) Equilibria with fixed $q(\psi)$ do continue to exist for a wide range of $Q(\psi)$ up to at 1 east $\bar{\beta} \sim 20-30 \%$. In some cases the evolution has been followed to $\bar{B}>50 \%$ without any problems. Cases with very deformed current profiles proved hard to converge at very high- $\beta$, but this may be a solely numerical problem or an inappropriate iteration scheme. 2) The magnetic axis shift is monotonic with the amount of peaking of $Q(\psi)$ on the magnetic axis. In cases where $Q(\psi)$ peaked away 
from the axis (hollow profile), the magnetic axis actually shifts inward from its location in the initial state.. 3) At high-B, the current density tends to be largest where the pressure gradient is largest, and severely distorted profiles can result. 4) Careful coll programing may be required to maintain a well centered equilibrium, but it appears that only poloidal field programming is required.

\section{ACKNOWLEDGMENTS}

The basic ideas for the equations used here are due to Harold Grad. Donald Stevens coded the iterative solution of the Generalized Differential Equation. I have also profitted from discussions with John Hogan, Glenn Bateman, and Dieter Sigmar.

\section{APPENDIX}

Averaged equations for large $\kappa_{\|}$follow. We assume $\kappa_{\|} \sim 1 / \varepsilon$ and expand $T$ in powers of $\varepsilon$ :

$\mathrm{T}=\mathrm{T}_{0}+\varepsilon \mathrm{T}_{1}+\cdots \cdot$

Inserting this expansion into the pressure equation (8), to order $\mathrm{E}^{-1}$ one finds

$\nabla \cdot\left[\frac{{ }_{\|}}{B^{2}} B\left(B \cdot \nabla T_{0}\right)\right]=B \cdot \nabla\left(\frac{K_{\|}}{B^{2}} B \cdot \nabla T_{0}\right)=0$.

Thus $\left(K_{\|} / B^{2}\right) B \cdot \nabla T_{0}$ is constant on a field line. Since $K_{\|} / B^{2}$ is positive, $B \cdot \bar{\nabla} T_{0}$ is of one sign, which is impossible since $T$ is single valued unless $\mathrm{B} \cdot \nabla \mathrm{T}_{0}=0$. Thus $\mathrm{T}_{0}$ is constant on magnetic surfaces: $\mathrm{T}_{0}(\psi)$. To next order Eq. (8) is

$\frac{\mathrm{dp}}{\mathrm{dt}}+\gamma \rho \nabla \cdot \mathrm{u}=(\gamma-1)\left[\mathrm{B} \cdot \nabla\left(\frac{\mathrm{K}_{\|}}{\mathrm{B}^{2}} \mathrm{~B} \cdot \nabla \mathrm{T}_{1}\right)+\mathrm{Q}\right]+\frac{\mathrm{p}}{\rho} \sigma \cdot$ 
But since $\langle B \cdot \nabla \phi\rangle=0$ for any $\phi$, the term in $T_{1}$ drops out of the surfaceaveraged equation. Thus we can assume $T(\psi)$, and since $p(\psi)=\rho T(\psi)$, we can also assume $\rho(\psi)$ in the surface-averaged equations. 


\section{REFERENCES}

1. C. Mercier, Nucl. Fusion 3, 89 (1963); 4, 213 (1964).

2. J. F. Clarke and D. J. Sigmar, Phys. Rev. Lett. 38, 70 (1977);

V. S. Mukhovatov and V. D. Shafranov, Nuc1. Fusion 11, 605 (1971).

3. R. A. Dory and Y-K. M. Peng, Nucl. Fusion 17, 21 (1977).

4. H. Grad and J. Hogan, Phys. Rev. Lett. 24, 1337 (1970).

5. H. Grad, in Advances in Plasma Physics, Vol. 5, p. 103, Wiley, New York, 1974.

6. H. Grad, P. Hu, and D. Stevens, Proc. NatZ. Acad. Sci. USA 72, 3789 (1975).

7. H. Lamb, Hydrodynamics, p. 245, Dover Publications, New York, 1945.

8. D. A. D'Ippolito, J. P. Freidberg, J. P. Goedbloed, and J. Rem, Plasma Physics and Controlzed Nuclear Fusion Research 1976, Vol. 1, p. 253, IAEA, Vienna, 1977.

9. G. Bateman, Nucl. Fusion 13, 227 (1973). 

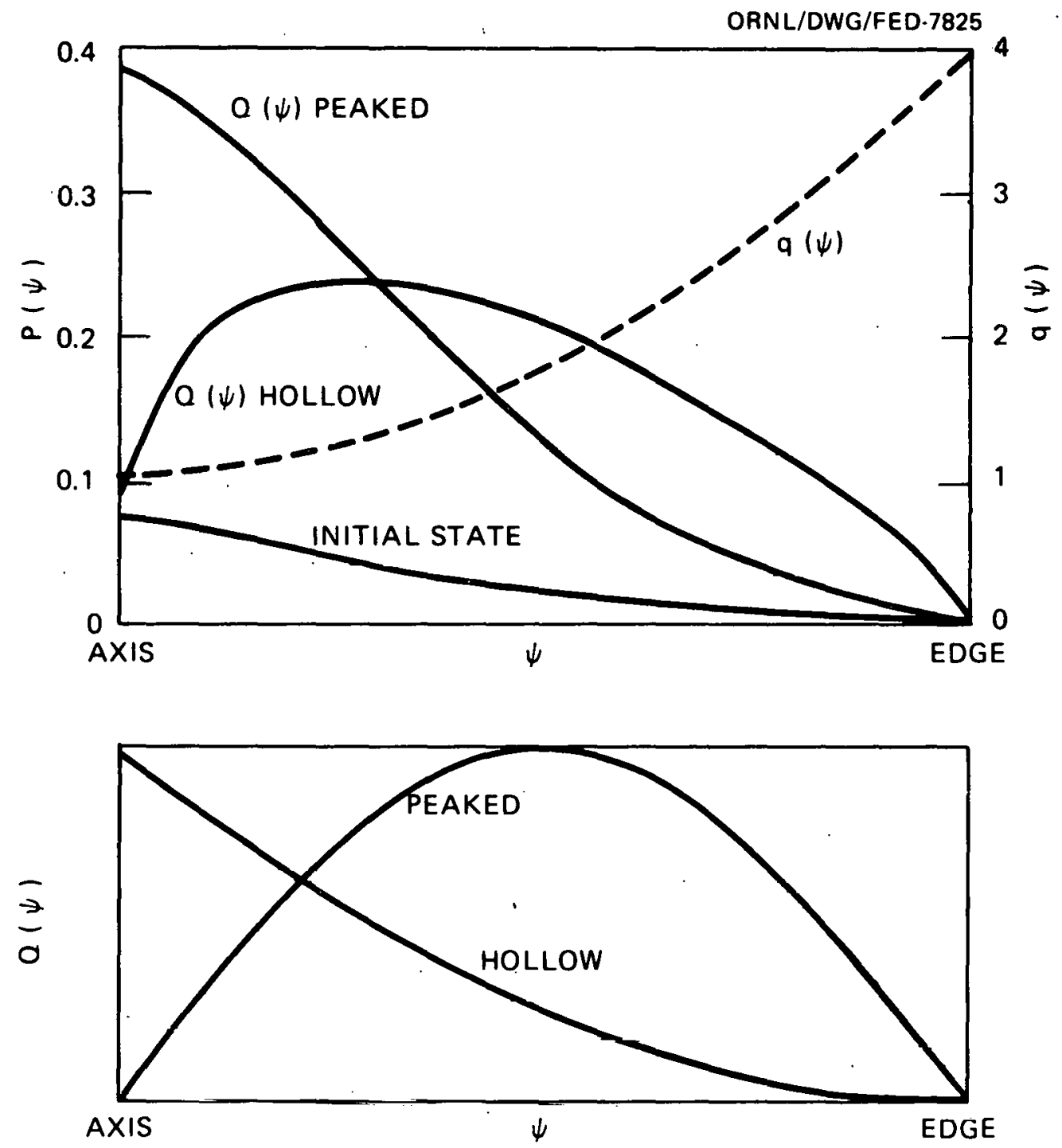

Fig. 1. Initial pressure profile evolves to either peaked or hollow profile depending on heat depocition $Q(\psi)$. The safety factor, $q(\psi)$, runs from one at the plasma center to four at the edge and is conserved during the heating. The heating profile, $Q(\psi)$, is either peaked or hollow. 
$Q(\psi)$ PEAKED
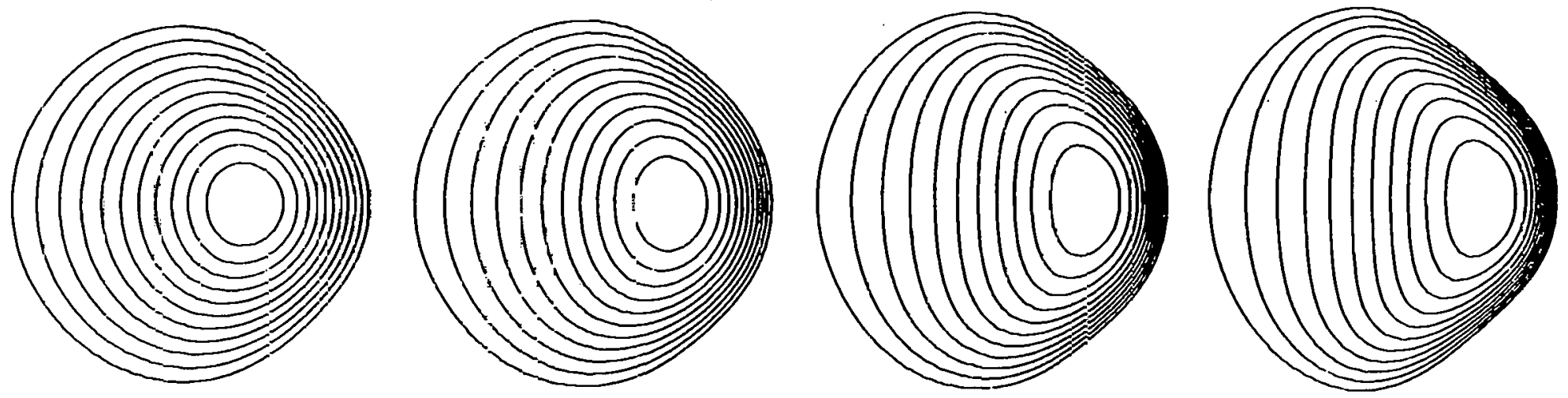

Q $(\Psi)$ HOLLOW
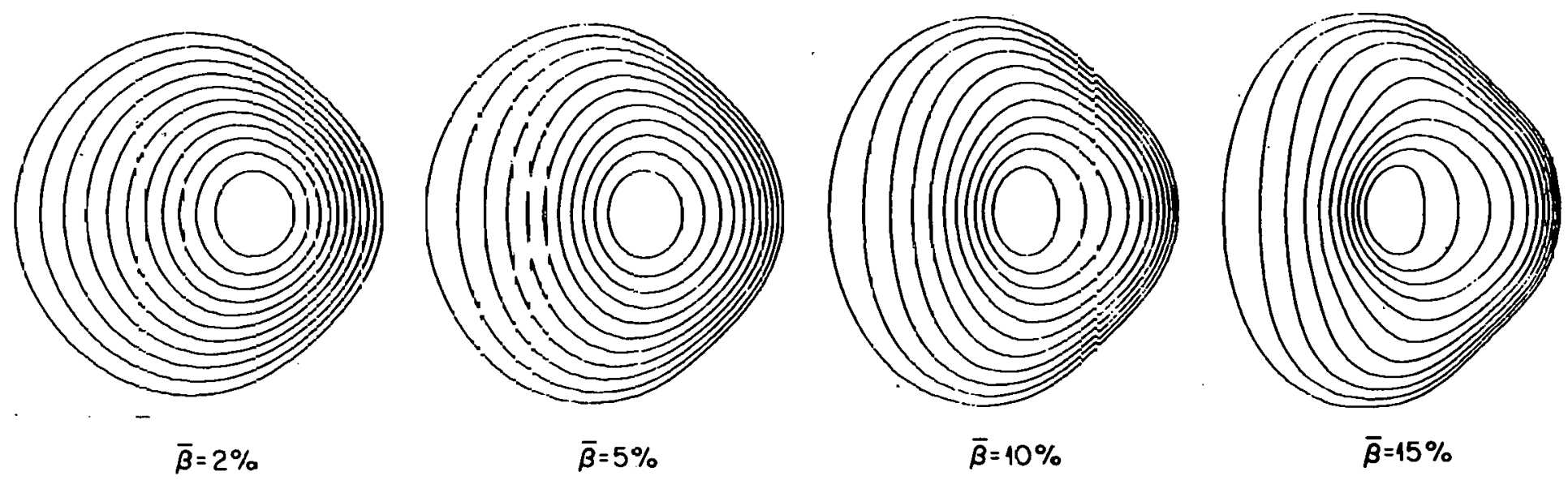

Fig. 2. Initi:l flux surfaces evolve to different shapes at high- $\beta$ defending on heating profile, $Q(\psi)$. 
ORNL/DWG/FED-7826
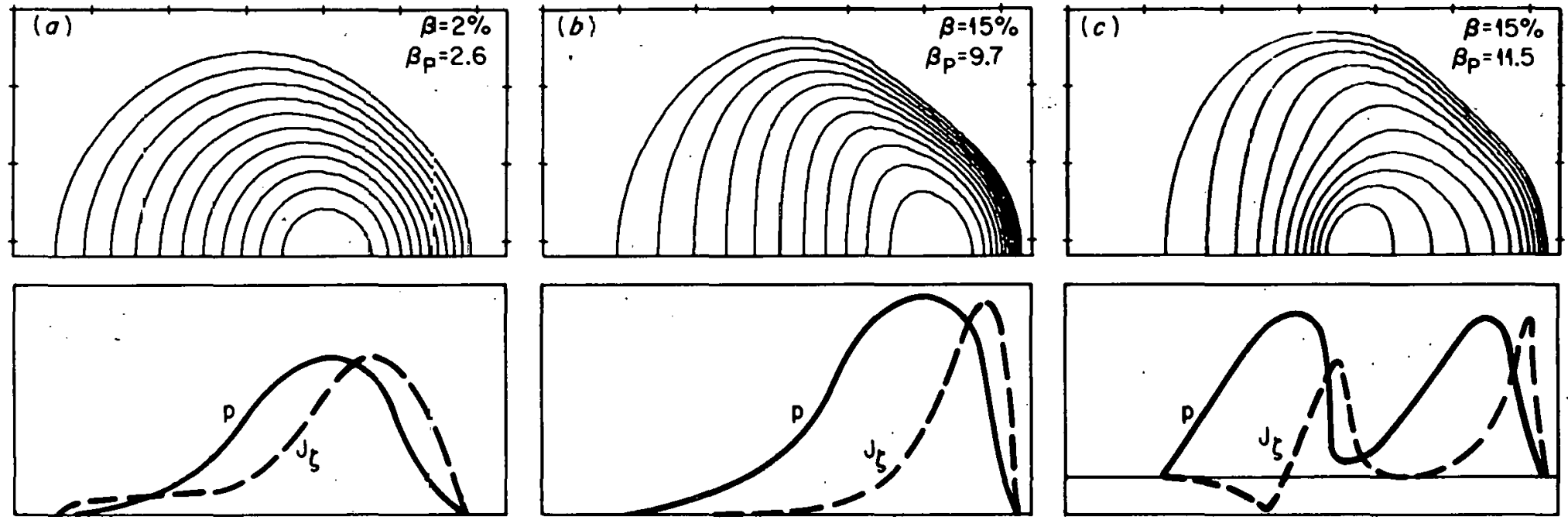

Fig. 3. (a) Initial pressure and toroidal current density on the equatorial plane. (b) Pressure and current density for peaked heating. Note current is largest where pressure gradient is largest. (c) With hollow heating profile, pressure and current are considerably distorted and a region of negative current appears. Again current peaks where pressure gradient is largest. 


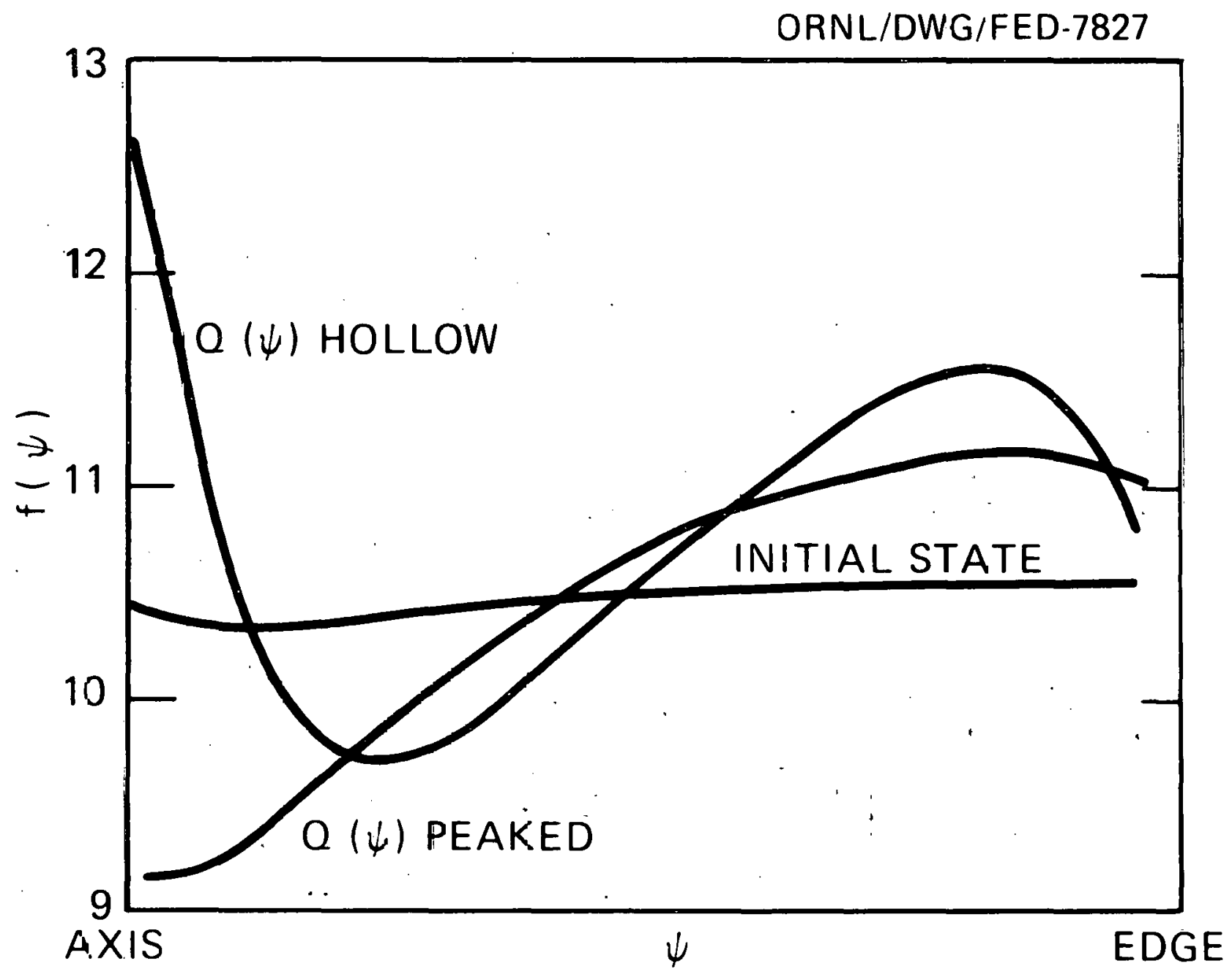

Fig. 4. Profiles of $f(\psi)=\mathrm{rB}_{\zeta}$. Initial state is approximately the vicuum $f$; final states show regions of diamagnetism (depressed $f$ ) and paramagnetism (elevated $f$ ). Note rise of $f$ at plasma edge. 


\author{
THE ELMO BUMPY TORUS - PRESENT AND FUTURE \\ EBT GROUP* \\ (presented by N.A. Uckan)
}

\title{
1. INTRODUCTION
}

The ELMO Bumpy Torus (EBT) experiment ${ }^{l}$ at ORNL was designed to circumvent the MHD stability problem encountered in standard bumpy tori by using the "minimum-B" properties of annular high-beta, hot-electron plasmas formed by microwave heating. The EBT combines the attractive features of both mirrors and tokamaks. The feasibility of this combined system has been demonstrated successfully in the EBT-I experiment and discussed at greater length elsewhere. ${ }^{1,2}$

The present status of the EBT research activities at ORNL is described briefly in the following sections.

\section{THE EBT PLASMA}

In EBT, there are two principal plasma components: mirror-trapped, high-energy electron annuli and a higher density, lower energy toroidal plasma. The parameters of these components vary widely with operating conditions. Control of the plasma properties can be maintained through control of the applied microwave power and the ambient neutral hydrogen density. After the plasma is created, and as the neutral density is lowered, three distinct reproducible regimes of operation are identifiable: the C-, T-, and M-modes. The C-mode occurs at low power or high neutral density. In this mode, very few energetic (annular) electrons are observed and no gross instabilities are seen, but low amplitude fluctuations in density are observable. The ions and electrons are relatively cold with temperatures of a few tens of electron volts.

*EBT Group: R. A. Dandl, F. W. Baity, D. B. Batchelor, J. A. Cobble, P. L. Colestock, H. O. Eason, G. R. Haste, C. L. Hedrick, S. Hiroe, H. Ikegami, E. F. Jaeger, N. H. Lazar, D. B. Nelson, L. W. Owen, D. A. Spong, B. H. Quon, and N. A. Uckan. 
As the power level is increased, at lower pressures, the stored energy in the energetic annuli increases significantly, the fluctuation amplitude drops to very low values, and a transition to the quiet $\mathrm{T}$-mode takes place. Figure 1 shows this transition clearly. The annular beta $\left(B_{A} \sim 5-15 \%\right)$ at which this transition takes place experimentally agrees with theoretical estimates of the beta value required to produce a local minimum in the magnetic field. ${ }^{3}$ Both the toroidal and annular plasma components are free from gross instabilities, and the toroidal core electron and ion temperatures rise by more than an order of magnitude. This quiet regime of operation is consistent with theoretical neoclassical transport models. At still lower pressure, the density drops rapidly and only the energetic electron annuli remain, fluctuating macroscopically, in the M-mode.

\section{PLASMA HEATING IN EBT}

In the present experiment, EBT-I, 1 the plasma is produced, heated, and stabilized by electron-cyclotron heating (ECH). Two microwave power supplies effectively give independent control of the hot electron annuli. and the coroldal plasind.

The magnetic field configuration and heating geometry in one section of EBT (EBT-I) are shown in Fig. 2. Collisionless electrons mirror along flux lines (dashed lines); in passing through mod-B surfaces (solid lines) that resonate with the applied microwave power (hatchedsolid lines), they gain energy from the resonant microwave field. On either side of each mirror midplane, on mod-B surfaces that cross the mirror torus axis, electrons are heated by $60 \mathrm{~kW}$ of microwave power at a frequency of $18 \mathrm{GHz}$. The location of these resonant zones provides heating of the toroidal plasma at all the minor radii and is called "bulk heating" or "primary resonant heating." The $10.6 \mathrm{GHz}, 30 \mathrm{~kW}$ of microwaves resonantly heat the electrons in off-axis annular regions near the mirror midplanes and produce the stabilizing high temperature, high-beta, hot-electron annulus. 'This 10.6-GHz "prof1le heating" suurce tailors the radial profile of the hot electron annuli and also provides parallel heating of toroidal plasma electrons. Second harmonic coupling 
is also effective in heating electrons to relativistic temperatures in the high-beta annuli.

\section{PRESENT AND NEAR-FUTURE EBT EXPERIMENTS}

In the present experiment, EBT-I, l the plasma is produced in a bumpy torus with a major radius of $1.5 \mathrm{~m}$ and a minor radius of $0.1-0.15 \mathrm{~m}$ by microwave heating (ECH) of electrons that in turn transfer heat to the ions by Coulomb collisions. It employs a toroidal array of 24 mirror coils which have magnetic fields of $1.0 \mathrm{~T}$ at their throats and $0.5 \mathrm{~T}$ at the mirror midplanes. The toroidal plasma has ion and electron temperatures in the range of $100-400 \mathrm{eV}$, densities approaching microwave cutoff $1+4 \times 10^{12} \mathrm{~cm}^{-3}$, and beta $\left(\beta_{\text {toroidal }}\right)$ of $5 \times 10^{-3}$.

EBT-I will become EBT-S in early 1978. EBT-S modifications are: increased magnetic fields ( 1.4 and $0.7 \mathrm{~T}$ ), increased microwave power (60 and $200 \mathrm{~kW}$ ), and increased frequencies (18 and $28 \mathrm{GHz}$ ). These changes are expected to increase the plasma parameters significantly and provide operating experience with the $28-\mathrm{GHz}$ power supplies. By adding relatively low current field shaping coils to the EBT-S structure, EBT-SA, substantial improvement to the confinement could be possible by an increase in the effective aspect ratio through symetrizing effects. These are called aspect ratio enhancement (ARE) coils.

A higher field, larger aspect ratio device, EBT-II, could come into operation in the early 1980's. EBT-II would be a superconducting device and would use microwaves at 70 and $120 \mathrm{GHz}$. EBT-II would allow operation at plasma parameters that approach reactor conditions. The operation of such a system will be a scale demonstration of much of the EBT reactor technology às well.

\section{EXPERIMENTAL RESULTS}

The plasma properties have been determined mostly in the T-mode because of the relatively long lifetimes and low fluctuation levels in this stable, well confined mode of operation. Outside the hot electron annulus, the plasma is dilute, cold, and unstable. Therefore, the 
density profile in the T-mode sharply increases near the hot electron annulus and is rather flat inside the minor cross section. The electron line density, measured by a microwave interferometer, is $\langle n \ell\rangle \sim 4 \times 10^{13}$ $\mathrm{cm}^{-2}$, resulting in an average $\mathrm{n}_{e} \sim 1-3 \times 10^{12} \mathrm{~cm}^{-3}$. Soft $\mathrm{x}$-ray measurements indicate electron temperatures of 100-400 eV with a nearly Maxwellian energy distribution.

The parameters characterizing the hot electron annulus are $\mathrm{n}_{\mathrm{eA}} \sim 1$ $4 \times 10^{11} \mathrm{~cm}^{-3}, \mathrm{~T}_{\mathrm{eA}} \sim 100 \mathrm{keV}$, and $0.1 \leqslant \mathrm{~B}_{\mathrm{A}} \leqslant 0.5$.

Spatially resolved measurements of the ambipolar electric field have been carried out with a heavy ion beam system. ${ }^{4}$ The potential may be either positive or negative relative to the wall in the plasma core, but it always shows a large positive peak ( $200 \mathrm{~V}$ ) at a position near the annulus. This space potential in EBT serves to improve the confinement properties of most ions and electrons and to reduce the influx of impurities from the plasma exterior. 5

The plasma stability in EBT is examined by measuring plasma fluctuations as one or more external parameters are varied. ${ }^{1}$ Recent studies involve the measurement of fluctuations using the field error as an external parameter. ${ }^{6}$ Magnetic field errors can give rise to a parallel (toroidal) current and in turn to instabilities in EBT. The field error effect becomes important when it exceeds a critical value of $(\delta \mathrm{B} / \mathrm{B})_{\mathrm{Cr}} \simeq$ $\sqrt{3 / 2}(\rho / R)$, where $\rho$ and $R$ are the particle gyroradius and major radius of the torus, respectively. ${ }^{6}$ Figure $3(\mathrm{a})$ shows a radially symmetric potential well measured with a global field correction such that the toroidal current is minimized. The symmetry in the potential profile excludes any possible formation of convective cells and is favorable to a neoclassical ambipolar transport. ${ }^{7-10}$ This desired symmerry breaks down when the global field correction is turned off. As shown in Fig. 3(b), the central plasma potential seems to be short-circuited to ground through the containment wall.

The effects of magnetic field error on plasma stability and containment in EBT are demonstrated in Fig. $4 .{ }^{6}$ The net toroidal current, the averaged plasma density, the averaged density fluctuation amplitude, and the plasma potential at the center and near the annulus are plotted 
together with the horizontal field error as a function of the current applied to the field correction coil. The measurements show that all the parameters change promptly as the field error scans across a critical value. The critical field error is estimated to be $(\delta \mathrm{B} / \mathrm{B})_{\mathrm{cr}} \simeq 0.6-1 \times$ $10^{-3} \sim \rho / R$. Field errors obtainable with superconducting coils are in the range of $10^{-6}$ to $10^{-7}$, so this effect does not pose a problem for future devices.

The toroidal core plasma is surrounded by a region of magnetic drift surfaces which intersect the wall. Observations from spectroscopic measurements show that the electron density and temperature in this region are appreciably lower than in the core plasma $\left(\mathrm{n}_{\mathrm{e}} \sim 10^{11} \mathrm{~cm}^{-3}\right.$, $\left.\mathrm{T}_{\mathrm{e}} \sim 30 \mathrm{eV}\right)$. The impurity lifetimes are in the neighborhood of $300 \mu \mathrm{sec}$. The dominant impurities are the lower charge states of aluminum, nitrogen, oxygen, and carbon. The characteristic CV (carbon $\mathrm{V}$ ) radiation was. unobservable, leading to the estimate that $n(\mathrm{CV}) / \mathrm{n}_{e}<6 \times 10^{-5}$ in the toroidal core plasma. The short lifetime of impurities, coupled with the requirement that they gain sufficient energy to overcome the potential barrier at the surface of the core plasma, provides a reasonable explanation of the apparent "divertor" efficiency of the surface plasma. 5

\section{THEORETICAL CONSIDERATIONS}

Several of the key aspects of EBT operation, such as confinement, equilibrium, ring formation, stability, transport, etc., have been modelen thenretically. In the area of particle confinement and equilibrium, codes have been developed to demonstrate existence of full three-dimensional currents carried by hot electron annuli.

From the linearized kinetic equations, the diffusion coefficients were first calculated by Kovrizhnykh ${ }^{11}$ in the limit of large radial electric fields. This work is extended by spong et al., ${ }^{8}$ to include arbitrary values of the ambipolar electric field which represent rea1istic modeling of the EBT plasma. Additional dependence upon the electric field is found. 8

Procedures and codes at three levels of sophistication are now available for analyzing the transport properties of the EBT system. 
These are a so-called "point model,"7 a radially resolved "fluid model,"9 and a "kinetic model."9 A "two-region model,"10 a routine between a "point model" and a full one-dimenșional "fluid model," has been formulated recently to permit rapid surveys of parameter space while including most of the essential physics. Results obtained from the zero-dimensional point model ${ }^{7}$ and from the two-region model ${ }^{10}$ are in reasonable agreement with the EBT-I experiment.

In the radial fluid model simulation, coupled equations for plasma density, neutral density, electron and ion temperatures, and ambipolar electric field are developed along with appropriate numerical solution techniques. 'l'his one-dimensional code is used for detailed study of profiles with self-consistent treatment of the electric field and compared with the EBT-I experimental data. It is found that this purely classical model ${ }^{9}$ predicts many features of EBT operation including steady-state solutions with radially inward pointing ambipolar fields. ${ }^{4}$

In EBT, the stability of the toroidal plasma component depends on the diamagnetism of the hot electron annulus which transforms the bumpy torus into an average minimum-B configuration. The hot electron diamagnetic currents act as "invisible coils" colocated with the bulk plasma and create a magnetic well when the beta value of the annulus exceeds a minimum value. The theoretical prediction for this critical value of beta in the annulus is about $5-15 \%$, and this is the experimentally observed value for the transition from the $\mathrm{C}$-mode to the quiet $\mathrm{T}$-mode. Once a magnetic well has been established by the annuli, a beta value of the toroidal core plasma comparable to the beta of the annuli can be achieved which is stable to all modes encompassed by guiding center or ideal MHD theories. ${ }^{3}$ This is a very encouraging result from the reactor application point of view.

The stability of the hot electron rings requires a Vlasov treatment because the characteristic drift frequencies exceed the ion-cyclotron frequency. Analysis of the Vlasov-Maxwell equations shows that the hot electron drift waves are stabilized by interference between the responses of the fast drifting electrons and the slowly drifting ions. ${ }^{3}$ The recent calculations of Dominquez and Berk ${ }^{12}$ indicate that the rings are 
stable provided the ratio of cold to hot electron density is sufficiently high (e.g., 10). These slab model calculations are presently restricted to stability of the hot electron rings, since the ion temperature was set equal to zero. A similar Vlasov model including ion temperature has also been used by Nelson et al. ${ }^{3}$

One can draw the following conclusions from the stability results to date. Apparently there is a coupled relationship between the toroidal core plasma and the hot electron rings: the toroidal core plasma provides the cooler electrons to stabilize the rings, while the hot electron rings provide the minimum-B necessary to stabilize the toroidal core plasma.

\section{REACTOR APPLICATION}

The experimental results from EBT have motivated a consideration of the EBT concept as the basis for a potential reactor. ${ }^{13}$ The first EBT reactor (EBTR) study was initiated in 1976 and provided the required starting point for continued assessment of the validity of the concept.

A power producing EBT reactor system is especially attractive because of its steady-state operation at high plasma pressure. EBT is a large aspect ratio device, so the accessibility problems are virtually eliminated, remote maintenance difficulties are eased, and relatively uniform structural loadings (due to weak toroidal curvature) alleviate engineering design problems. No pulsed fields are required for EBT operation; therefore, it is less likely to be subject to thermal and mechanical fatigue than reactors with large pulsed fields and short bursts of fusion power. The details of the reactor design are discussed in greater length in Ref. 13.

A comparison of the parameters of EBT-I and those projected for EBT-S/SA, EBT-II, . . ., EBTR yields an interesting result. Virtually all the dimensionless parameters which influence stability are roughly the same in EBT-I, EBT-II, and in the projected EBTR. Thus, the following dimensionless parameters are either the same or in the direction of increased stability: annular beta, ratio of gyroradii to various scale lengths, field errors, aspect ratio, ratio of cold to hot electron 
density, ratio of electron to ion temperature, ratio of electron plasma frequency to cyclotron frequency, and ratio of ambipolar potential to temperature. The beta of the toroidal core plasma, and, to a lesser extent, the collisionality are factors which change appreciably. The approximate constancy of these dimensionless parameters which are known to influence stability is very encouraging, and the extrapolation of EBT-I results to EBTR is feasible. The first test of toroidal beta limitations on stability/instability will be demonstrated in EBT-II, where the toroidal core beta will be about $10 \%$. Collisionality, $\nu / \Omega$, differs from EBT-I to EBTR only by factors of two and ten for electrons and ions, respcctively.

\section{REFERENCES}

1. R. A. Dandl et a1., in Plasma Physics and Controlled Nuclear Fusion Research 1974, Vol. II, p. 141, IAEA, Vienna, 1975;

R. A. Dandl et al., Research Program for Plasma Confinement and Heating in ELMO Bumpy Toms Devices, ORNL/TM-4941, Oak Ridge National Laboratory, Oak Ridge, TN (June 1975); The ELMO Bumpy Torus Program, ORNL/TM-5451, Oak Ridge National Laboratory, Oak Ridge, TN (April 1976); R. A. Dand1, H. O. Eason, and H. Ikegami, "Microwave Hlasma Heating at the Electron Cyclotron Frequency," to be published in Nuclear Fusion.

2. C. L. Hedrick et al., in Plasma Physics and Controlled Nuclear Fusion Research 1976, Vol. II, p. 145, IAEA, Vienna, 1977.

3. D. B. Nelson and C. L. Hedrick, Macroscopic Stability and Beta Limits in the ELMO Bumpy TOms, ORNL/TM-5967, Oak Ridge National Laboratory, Oak Ridge, TN (December 1977); G. E. Guest et al., Phys. Fluids $\underline{18}, 871$ (1975).

4. P. L. Culestuck el dl., "Implementaliun of the Heavy Iun Beam Probe Diagnostic System for EBT," and F. M. Bieniosek et al., "Heavy Ion Beam Probe Measurements on the EBT Device," IEEE Int1. Conf. Plaoma Science, Troy, New York (May 1977); P. L. Colestock, K. A. Connor, R. L. Hickok, and R. A. Dandl, submitted to Phys. Rev. Lett. 
5. N. H. Lazar (Oak Ridge National Laboratory), private communication; E. S. Warden, H.W. Moos, and N. H. Lazar, Observations of Low Charge State Impurities in EBT, ORNL/TM-5899, Oak Ridge National Laboratory, Oak Ridge, TN (May 1977).

6. B. H. Quon et al., Effects of Global Fiezd Errors on ELMO Bumpy Torus, ORNL/TM-6075, Oak Ridge National Laboratory, Oak Ridge, TN (October 1977), submitted to Phys. Rev. Lett.

7. C. L. Hedrick et al., A Simple Neoclassical Point Model for Transport and Scaling in EBT, ORNL/TM-5490, Oak Ridge National Laboratory, Oak Ridge, TN (April 1977); Nucl. Fusion 17, 237 (1977).

8. D. A. Spong et al., Kinetic Transport Properties of a Bumpy Torus with Finite Radial Ambipolar Field, ORNL/TM-6215, Oak Ridge National Laboratory, Oak Ridge, TN, to be published.

9. E. F. Jaeger et a1., A Numerical Model for Radial Transport in ELMO Bumpy Torus, ORNL/TM-6013, Oak Ridge National Laboratory, Oak Ridge, TN (November 1977); E. F. Jaeger et al., "A Kinetic Transport Model for the ELMO Bumpy Torus" (to be published as an ORNL/TM, Oak Ridge National Laboratory); E. F. Jaeger et al., "Neoclassical Transport in the ELMO Bumpy Torus," submitted to Phys. Rev. Lett.

10. C. L. Hedrick, Bull. Am. Phys. Soc. 22, 1146 (1.977).

11. L. M. Kovrizhnykh, Zh. Eksp. Teor. Fiz. 56, 877 (1969) [Sov. Phys.JETP 29, 475 (1969)] .

12. R. R. Dominguez and H. L. Rerk, Stability of Interchange Modes in a Hot-ELectron Plasma, UCRL-79268, Lawrence Livermore Laboratory, Livermore, CA (April 1977), submitted to Phys. Fluids.

13. N. A. Uckan et al., The ELMO Bumpy Torus (EBT) Reactor, ORNL/TM6084, Oak Ridge National Laboratory, Oak Ridge, TN, in preparation; D. G. McAlees et al., The ELMO Bumpy Torus Reactor ( $E^{\prime} B^{\prime} I^{\prime} K$ ) Reference Design, ORNL/TM-5669, Oak Ridge National Laboratory, Oak Ridge, TN (November 1976). 


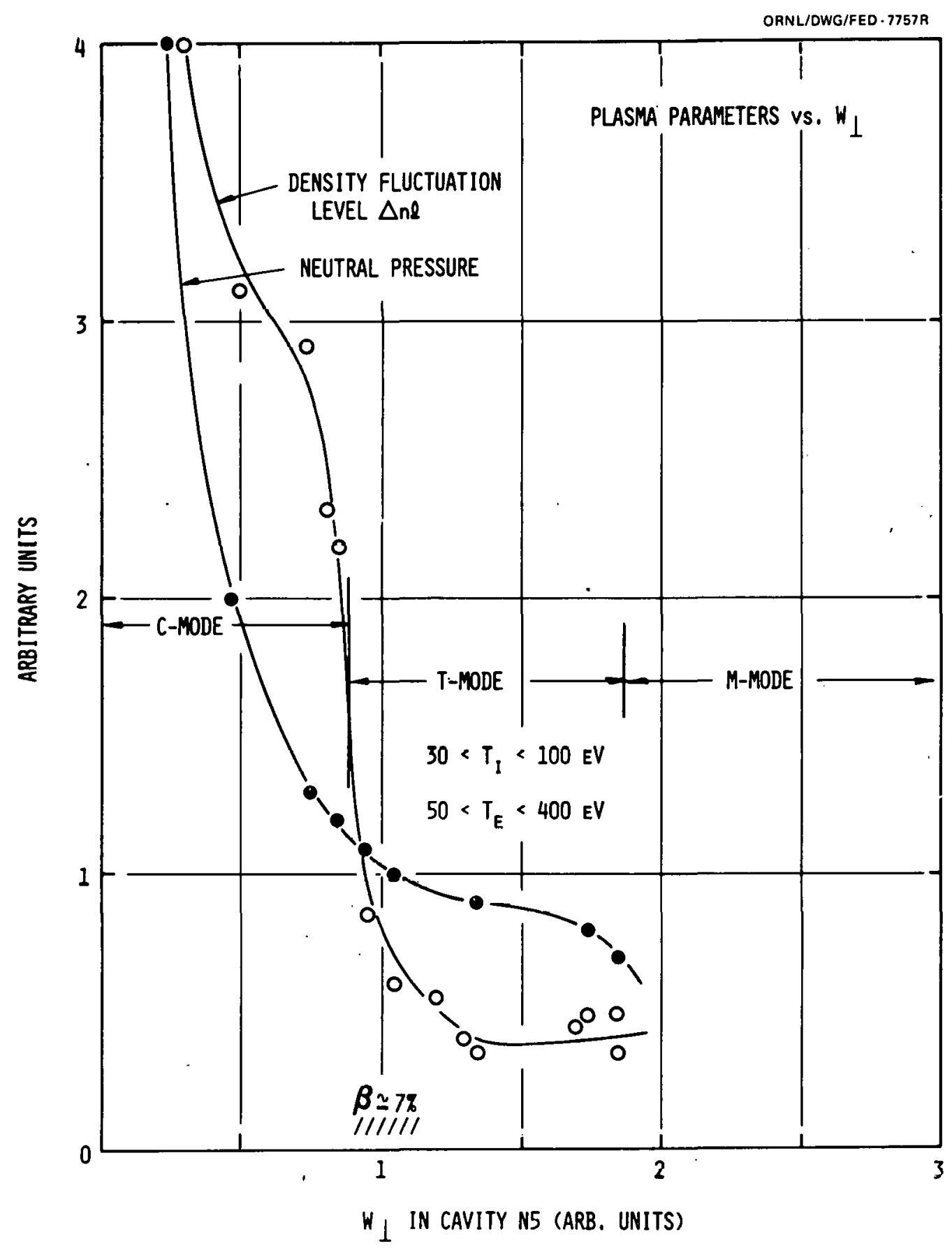

Fig. 1. Density fluctuation level vs stored energy, The sharp decrease in the fluctuation level between the $\mathrm{C}$ - and $\mathrm{T}$-modes corresponds to theoretical estimates of the annular beta necessary to produce a local minimum in the magnetic field. 
ORNL-OWG 74-2066A-R2

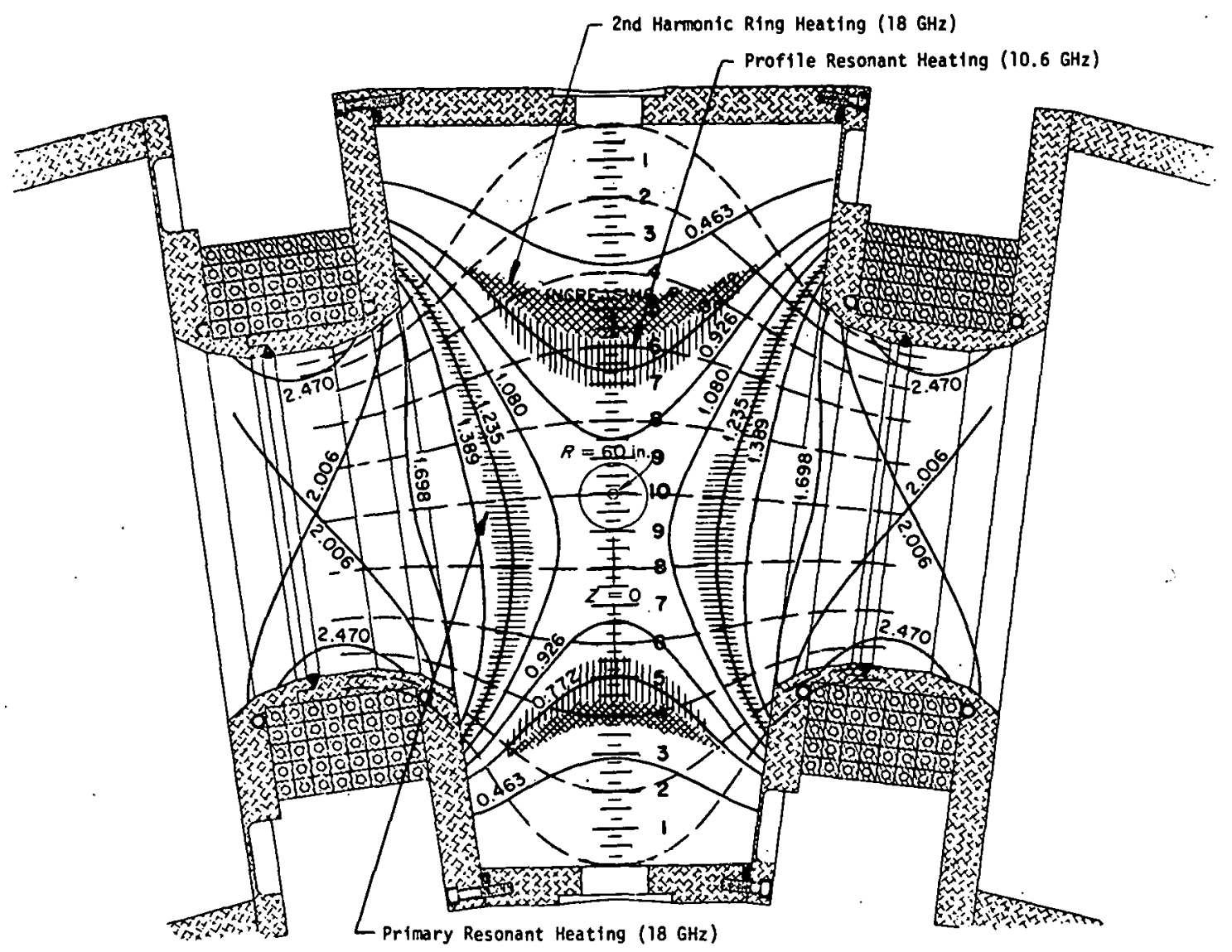

ЕВT Mod-B Contours (-), flux Lines $(--)$, and Heating Geometry $(/ / 1$,$) , ($

Fig. 2. Configuration of magnetic field in the ELMO Bumpy Torus. Two microwave frequencies $(10.6 \mathrm{GHz})$ are fed from the opening on the inside wall of the cavity. The wave mode at the injection port is "ordinary" rather than "extraordinary." The hot electron ring (runaway electrons) is observed to be a narrow belt encircling the local 2nd harluvilic resonance (for $18 \mathrm{GHz}$ ) reginn in the midplane. The maximum microwave heating takes place at the cyclotron resonance zone (hatched in the figure). This makes it conveniently possible to control the density and temperature profiles in the bumpy torus and also analogously applicable to tokamak piasmas. 
GLOBAL FIELD CORRECTION PRESERVES SYMMETF. IN POTENTIAL PROFILE:

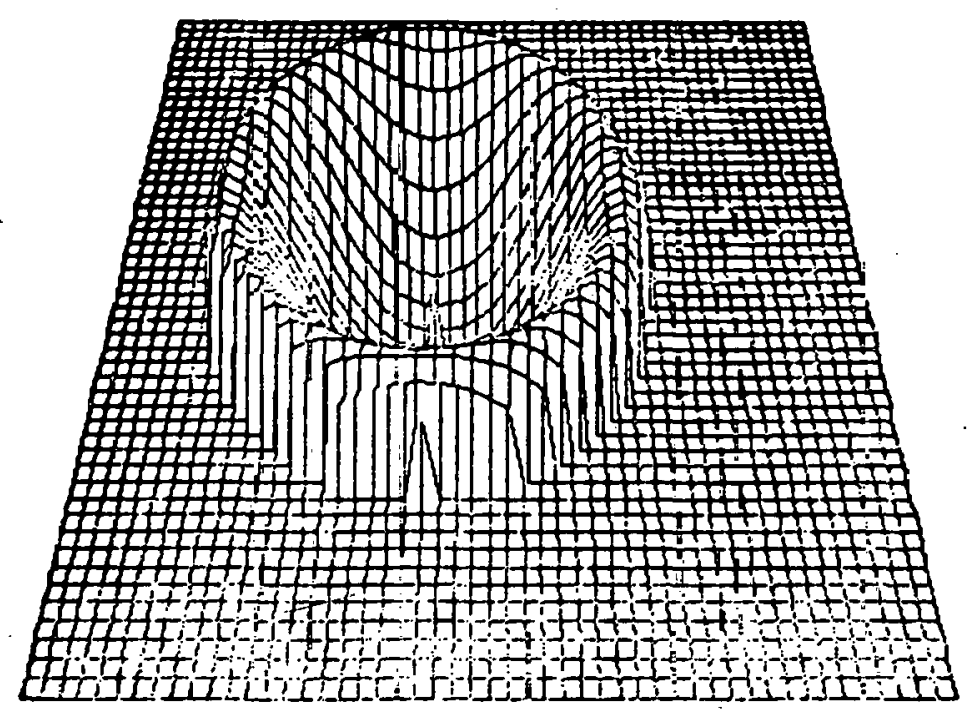

a) WITH FIELD

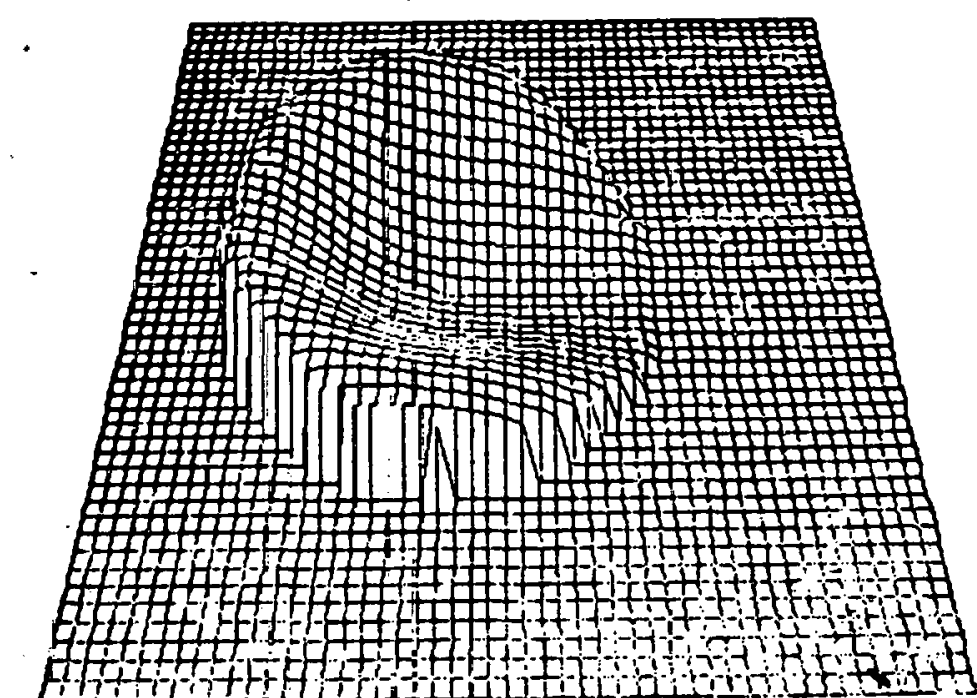

t) . WITHOUT FIELD CORRECTION

Fig. 3. The plasna potential profiles measured by using a rubidium ion beam probe $(15 \mathrm{kV}):$ a) is the two-dinensional profile generated using a spline fit to data obta-ned with a proper field correction on EBI; (b) is measured without field corrections. 


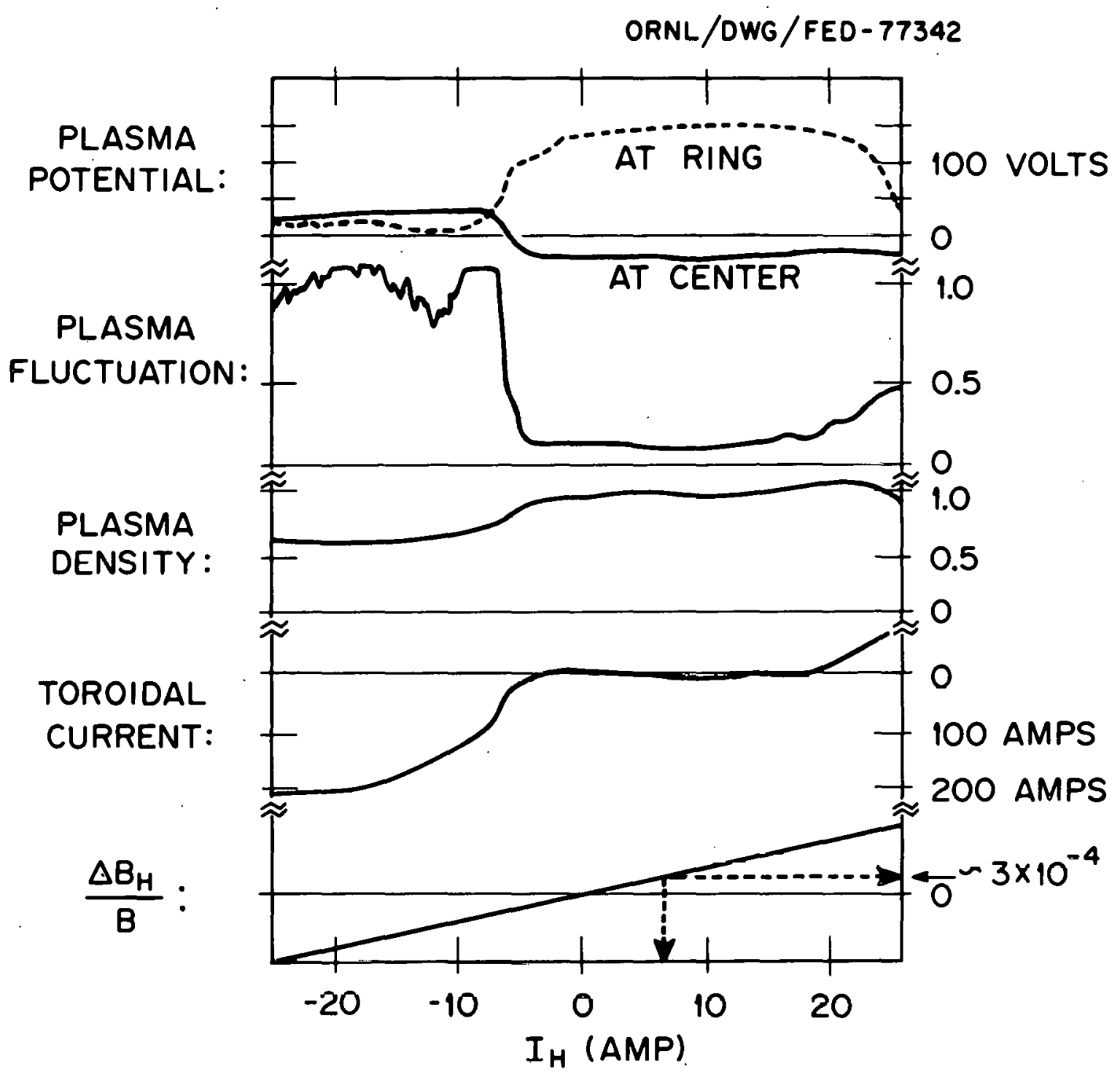

Fig. 4. Correlations of several parameters measured simultaneously as the horizontal field error scans in the range of $\pm 1-2 \times 10^{-3}$. The probable system global error is estimated to be $3 \times 10^{-4}$, as indicated by the arrowhead. 


\section{THIS PAGE}

\section{WAS INTENTIONALLY LEFT BLANK}


ORNL/TM-6273

Dist. Category UC-20g

INTERNAL DISTRIBUTION

$\begin{array}{ll}\text { 1. } & \text { L. A. Berry } \\ \text { 2. J. D. Callen } \\ \text { 3. R. A. Dandl } \\ \text { 4. R. A. Dory } \\ \text { 5. G. G. Kelley } \\ \text { 6. H. H. Haselton } \\ \text { 7. P. N. Haubenreich } \\ \text { 8. M. S. Lubell } \\ \text { 9. O. B. Morgan } \\ \text { 10. H. Postma } \\ \text { 11. M. W. Rosenthal } \\ \text { 12. J. Sheffield } \\ \text { 13. D. Steiner }\end{array}$
14-28.
R. G. Bateman
29-46. D. B. Nelson
47-61. D. J. Sigmar
62-76. N. A. Uckan
77-78. Laboratory Records Department
79. Laboratory Records, ORNL-RC
80. Document Reference Section
81-82. Central Research Library
83. Fusion Energy Division Library
84. Fusion Energy Division
Communications Center
85. ORNL Patent Office

\section{EXTERNAL DISTRIBUTION}

86. Bibliothek, Max-Planck Institute für Plasmaphysik, 8046 Garching bei Muinchen, Federal Republic of Germany

87. Bibliothèque, Service du Confinement des Plasmas, C.E.A., B.P. No. 6, 92, Fontenay-aux Roses (Seine), France

88. J. F. Clarke, Office of Fusion Energy, G-234, Department of Energy, Washington, DC 20545

89. Harold K. Forsen, Exxon Nuclear Co., Inc., 777 106th Avenue N.E., C-000777, Bellevue, WA 98009

90. Harold P. Furth, Princeton Plasma Physics Laboratory, Princeton University, Forrestal Campus, P.0. Box 451, Princeton, NJ 08540

91. Roy W. Gould, Calffornia Institute of Technology, Mail Stop 116-81, Pasadena, CA 9.1.1.25

92. Robert L. Hirsch, Exxon Research and Engineering, P.O. Box 101, Florham Park, NJ 07932

93. Library, Centre de Recherches en Physique des Plasma, 21 Avenue des Bains, 1007, Lausanne, Switzerland

94. Library, Culham Laboratory, United Kingdom Atomic Energy Authority, Abingdon, Oxon, 0X14 3DB, United Kingdom

95. Library, FOM-Institut voor Plasma - Fysica, Rijnhuizen, Jutphaas, Netherlands

96. Library, Institute for Plasma Physics, Nagoya University, Nagoya, Japan 464

97. Library, Laboratorio Gas Ionizzati, Frascati, Italy

98. Oscar P. Manley, Office of Fusion Energy, G-234, Department of Energy, Washington, DC 20545

99. D. Pfirsch, Institute for Plasma Physics, 8046 Garching bei München, Federal Republic of Germany

100. J. B. Taylor, Culham Laboratory, United Kingdom Atomic Energy Authority, Abingdon, Oxon, OX14 3DB, United Kingdom

101. Director, Research and Technical Support Division, Department of Energy, Oak Ridge Operations, P.0. Box E, Oak Ridge, TN 37830

102-277. Given distribution as shown in TID-4500, Magnetic Fusion Energy (Distribution Category UC-20g, Theoretical Plasma Physics) 